\title{
Numerical modelling of lumpy clay landfill
}

\author{
J. Najser, D. Mašín* and J. Boháč \\ Faculty of Science, Charles University in Prague, Czech Republic
}

\begin{abstract}
Two trial motorway embankments built on a landfill consisting of clayey lumps were monitored over the period of 3 and 5 years respectively. The subsoil of the embankment was instrumented by hydrostatic levelling profiles, pore pressure transducers and depth reference points installed in boreholes. An advanced constitutive model for clays (hypoplastic model for clays with meta-stable structure) was used for numerical modelling of both case histories. Basic hypoplastic model for clays was calibrated using isotropic compression tests and triaxial compression tests on reconstituted clay. Three additional model parameters describing the effects of lumpy structure were calibrated using oedometer tests on specimens prepared from scaled down lumpy material (material with smaller size of clay lumps). The performance of the model was evaluated by comparison with the results of the centrifuge model of self weight consolidated landfill. Finally, the hypoplastic model was used for simulation of both trial embankments and the results were compared with in situ measurements. The degradation of the lumpy structure of the upper layer of the in situ landfill due to weathering was back analyzed using monitoring data.
\end{abstract}

KEY WORDS: clay; hypoplasticity; double porosity; soil structure; high compressibility; embankment

* Correspondence to: David Mašín, Faculty of Science, Charles University in Prague, Albertov 6, 12843 Prague 2, Czech Republic. E-mail: masin@natur.cuni.cz 


\section{INTRODUCTION}

In North-Western Bohemia (Czech Republic), large areas are influenced by open cast mining of brown coal (Fig. 1). The coal seam is up to $30 \mathrm{~m}$ thick and it is situated at depths of up to $150 \mathrm{~m}$. The overburden is composed of stiff clays and claystones, which are excavated during the mining process and placed into large spoil heaps as irregularly shaped lumps ranging from dust size up to blocks of $0.5 \mathrm{~m}$ in diameter. Initially, external landfills are created, whose thickness reaches up to $100 \mathrm{~m}$. In the later phases of the exploitation, when the mine pits are large enough, they are backfilled with the excavated soil. The thickness of these internal landfills is up to $200 \mathrm{~m}$. The total area of landfills exceeds $100 \mathrm{~km}^{2}$. Due to the large area affected by mining, landfill areas have a potential for engineering development and they need to be considered as a construction subsoil, which implies a need for a detailed study of their mechanical behaviour.

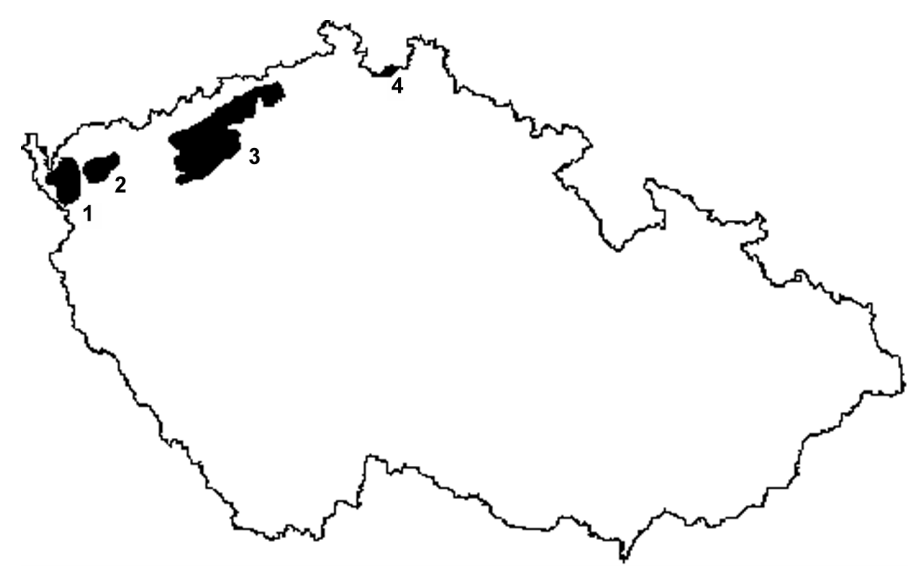

Fig. 1: Tertiary basins with brown coal seam in NW Bohemia: 1 - Cheb Basin, 2 - Sokolov Basin, 3-Most Basin, 4 - Zittau Basin.

The lumpy clay landfill material represents an example of a double porosity soil with two distinct pore systems. In addition to the voids within intact clay lump the double porosity soil has also voids between the clay lumps. Voids within clay lumps are measured by the intragranular porosity $\left(n_{i}\right)$, which is defined as the ratio of the voids within the lumps and the total volume of the lumps. The size of the voids between clay lumps is measured by the intergranular porosity $\left(n_{e}\right)$, defined as the ratio of the voids between the lumps and the total volume of the soil. The total porosity of the fill $n_{t}$ can then be calculated from

$$
n_{t}=n_{i}\left(1-n_{e}\right)+n_{e}
$$


and it may reach up to $70 \%$ in the case of the lumpy clay landfills [1]. An alternative definition of the intragranular porosity (volume of intra-aggregate pores divided by total volume of soil) was put forward by Koliji et al. [2].

Within the scientific literature, the term "double porosity" material is used for any material with two distinct pore systems. Most of the research on double-porosity materials is related to the behaviour of unsaturated fine-grained soils. In particular, the soil compacted on the dry side of optimum water content is often found to have a distinct double-porosity structure, with the size of micro-pores (intragranular pores) of the order of $0.1-1 \mu \mathrm{m}$ and the size of macro-pores of the order of 10-100 $\mu \mathrm{m}$. The aggregates of fine particles are in this case formed naturally by the physico-chemical phenomena at the clay particle level. For the related literature, see for example [3-9].

The double-porosity material studied in this paper is different in nature from the material described in the previous paragraph. The size of the lumps, and thus also the size of the macro-pores, is of the order of magnitude of 0.1-1 m, and thus 4 orders of magnitude larger then in the case of typical compacted fine-grained soil. The lumps are created by the artificial mechanical disintegration of the more-or-less homogeneous deposit of fine-grained soil of different consistency. The literature describing the mechanical behaviour of such double-porosity media is more scarce. Most of the research was associated with the behaviour of the lumpy clay landfills originating as a by-product of open cast mining, or with the investigation of the mechanical properties of the clay lumps dredged out from the seabed. Experimental investigation of the behaviour of a dredged lumpy clay used in Singapore for land reclamation was described by Robinson et al. [10] and Karthikeyan et al. [11]. Similar material was used for land reclamation in Halmstad Harbor, Sweden [12]. Further experimental studies on the behaviour of dredged lumpy material are in $[13,14]$.

A summary of the field monitoring of the behaviour of mining landfills from various sites can be found in [15-17]. The following common features were described from different sites: large and nonuniform compressibility associated with the degradation of the lumpy structure, creep of the landfill and collapsible behaviour of the fill after the first saturation. Soon after filling, the soil can be described as a granular material (Fig. 2a). Over time and with increasing load, the structure of the fill changes, the macrovoids are reduced in size and filled with clay (Fig. 2b) and the overall mechanical behaviour then resembles single porosity fine grained soil [18]. The behaviour of the landfill at each site is influenced by the specific conditions - mechanical properties of the lump material, shape of the lumps, lump size distribution, compaction during filling, groundwater 
conditions and stress history.

The fundamental principles governing the behaviour of double-porous media were studied by a number of authors. The general consolidation theory of double-porous medium was proposed by Aifantis [19] and Wilson and Aifantis [20], and it was later on refined by Khalili and Valliapan [21] and Yang et al. [22,23]. These works, however, focus on the hydro-mechanical coupling and consolidation of double-porous media, rather then on an accurate quantitative description of the mechanical behaviour of lumpy material. The behaviour of these soils is fairly complex, due to the combination of the non-linear mechanical behaviour of the lumps and degradation of the doubleporosity structure, which is itself controlled by various phenomena (mechanical loading, weathering processes, etc.). Considering all these effects within models that take into account micro-mechanics of such a material may be a tedius task. Among few examples, Doležalová and Kořán [24] presented DEM modelling of lumpy material. Callari and Federico [25] compared consolidation reponse of double porous medium predicted by the micro-mechanical model based on FEM and predictions by a model of a homogeneous equivalent double porosity medium.

Due to the difficulties in accurate description of the micro-mechanical behaviour of lumpy material, it is often preferable to use phenomenological models based on the experimental observation of the overall mechanical behaviour of these soils. A constitutive framework for the mechanical behaviour of soils with the double porosity structure was developed by Koliji et al. [2] based on experimental data summarised by Koliji et al [26]. Oedometer tests on aggregated soil revealed that the yield limit of the double porosity soil is a function not only of stress state and stress history, but also of the particular soil structure. Based on the experimental results, a new state parameter was proposed to quantify the double porosity soil structure. Similar approach was used by Mašín et al. [27]. More details on constitutive modelling of double porosity soils are given in Sec. 3. 

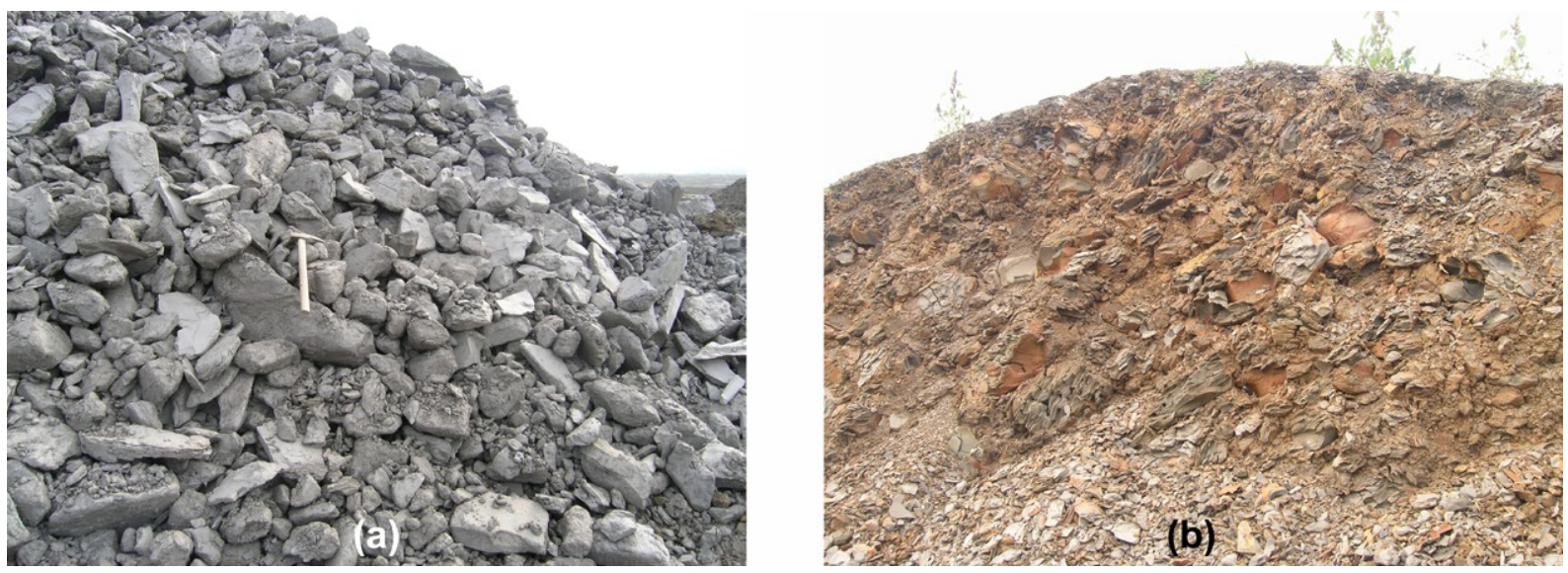

Fig. 2: Landfill during construction (a) and after 15 years of self-weight consolidation and weathering (b).

In this paper, we focus on the mechanical behaviour of double-porous material with large interaggregate pores (lumpy material). The behaviour of this material is described using a phenomenological constitutive model based on the overall mechanical response of this complex soil (namely, a hypoplastic model enhanced by the effects of structure). The paper is organised as follows. After the introductory sections, the calibration of the hypoplastic model for structured clays is described based on laboratory experiments on the reconstituted and undisturbed clayfill material and lumpy clayfill material with scaled-down granulometry. The model is then evaluated by means of finite element simulations of the centrifuge model of an embankment on a lumpy clay landfill with scaled-down granulometry, to demonstrate its predictive capabilities. Subsequently, two realsize motorway embankments on the landfill are simulated using the adopted models. Finally, the inter-granular porosity degradation of the landfill during 15 years between heaping and construction of the embankments is quantified by means of inverse analysis of the monitored data.

\section{TRIAL EMBANKMENTS}

A new motorway between Prague (Czech Republic) and Dresden (Germany) crosses 20 to 30 years old landfill of the Most basin (Fig. 1). The total length of the sections crossing the old lumpy clay landfills is approximately $6 \mathrm{~km}$. Before the construction of the motorway, two trial embankments had been built on its route. The thickness of the landfill at the site was approximately $30 \mathrm{~m}$. The first embankment (Embankment 1) was located at a site where $3.5 \mathrm{~m}$ thick permeable layer of fly ash had been deposited on the top of the landfill after the landfill heaping. No fly ash was present at the site of the second embankment (Embankment 2). The embankments were monitored for 3 and 5 years respectively. 
The landfill material at the site of interest possesses an average total porosity of $40 \%$, liquid limit of $72 \%$ and plasticity index of $45 \%$. The mineralogical composition determined by X-Ray diffraction analysis is $36 \%$ kaolinite, $25 \%$ smectite, $11 \%$ illite and $21 \%$ quartz. The process of the landfill construction is as follows: After the excavation, the clay lumps are transported by conveyor belts and filled with stowing machines with rotating boom. In the process, the lumpy material forms conical heaps, and some size segregation of the lumps takes place. Therefore, the resulting landfills are not homogeneous and differential settlements should be expected. Generally, there has been lack of information on the method of filling and on the initial conditions (for example existence of effective drainage) and therefore the prediction of the mechanical behaviour of the old landfills is difficult.

Embankment 1 was constructed in April 1998. The embankment was $6 \mathrm{~m}$ high with crest dimensions 35 by $4.5 \mathrm{~m}$ and slopes graded at 1:1.5 (Fig.3a). As already indicated, $3.5 \mathrm{~m}$ thick layer of permeable fly ash was present at the site. The monitoring included the measurement of the settlement of the landfill surface by hydrostatic leveling at the base of the embankment, the measurement of the landfill settlement in different depths below the embankment by depth reference points and pore pressure gauges in the embankment subsoil. Flexible plastic tubes for the hydrostatic leveling were installed in three profiles perpendicular to the axis of the embankment. The position of the depth reference points was measured in two boreholes with eight externally mounted free moving magnetic rings. The deepest reference point was installed $28.5 \mathrm{~m}$ below the landfill surface. Gauges for the measurement of pore water pressure were installed $6 \mathrm{~m}$ and $7.5 \mathrm{~m}$ below the ground surface.

Embankment 2 was constructed in August 2001. No fly ash was present at this site, the embankment was thus constructed on a $1.4 \mathrm{~m}$ thick rubble layer to enhance permeability of the embankment base. It was $7.5 \mathrm{~m}$ high with crest dimensions 20 by $35 \mathrm{~m}$ with slopes graded at 1:1.5 (Fig. 3b). The embankment was instrumented similarly to the first embankment, with two hydrostatic levelling profiles at the base of the embankment, depth reference points in two boreholes (11 in total) and the pore pressure transducers installed in three different depths $(3 \mathrm{~m}, 6 \mathrm{~m}$ and $10 \mathrm{~m}$ below the original surface). Both embankments were monitored until September 2004. A detailed description of the monitoring and discussion of the results was presented by Škopek [28] and Škopek and Boháč [29]. 

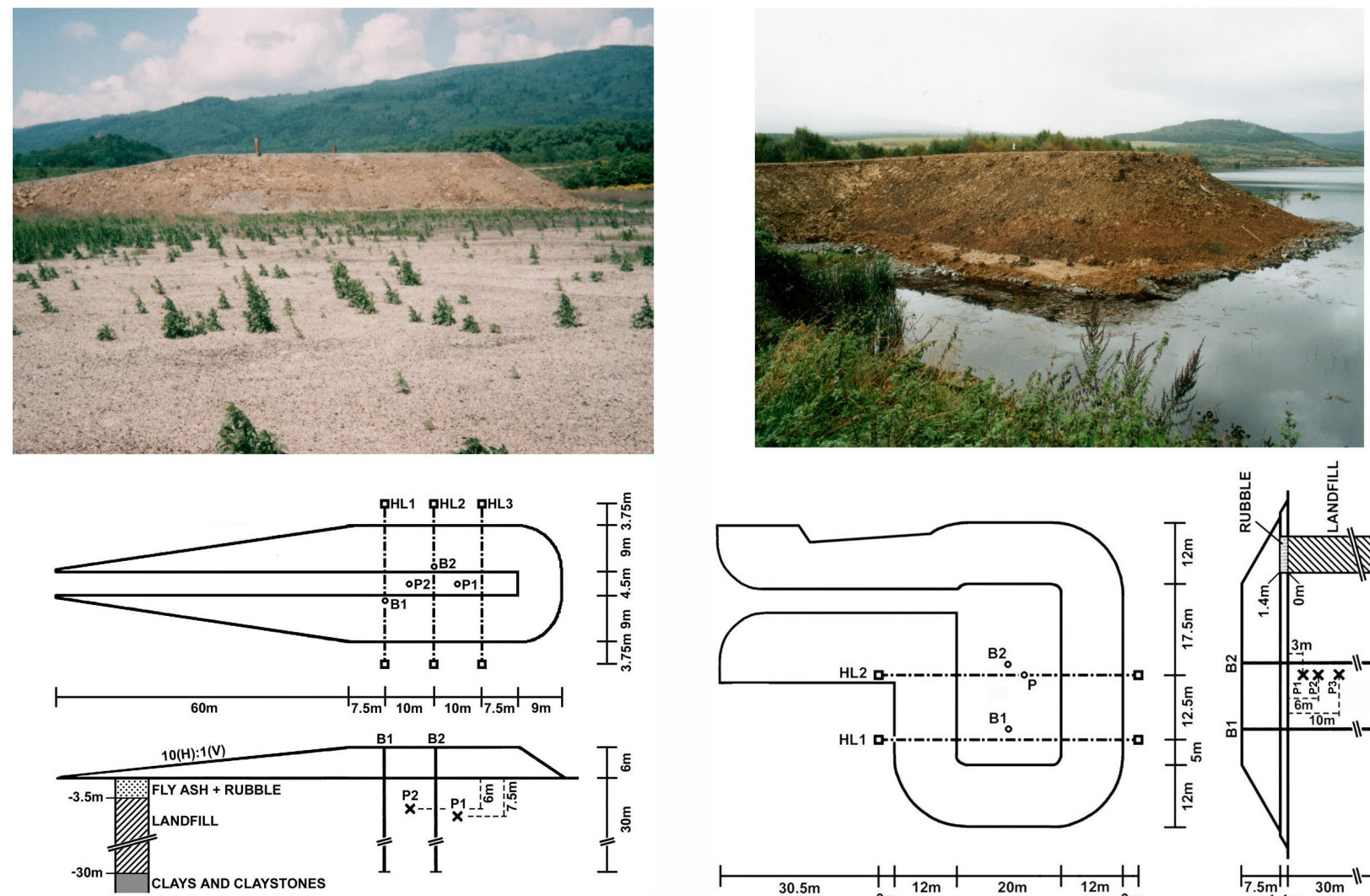

(a)

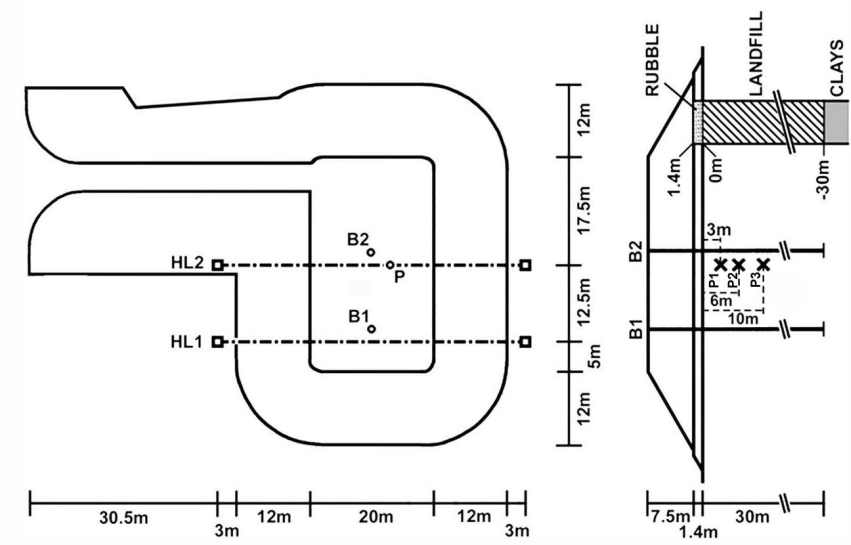

(b)

Fig. 3: Embankment 1 (a) and Embankment 2 (b), their instrumentation and geology of subsoil. (HL hydrostatic levelling profiles, $P$ - pore pressure gauges, $B$ - boreholes with depth reference points). 


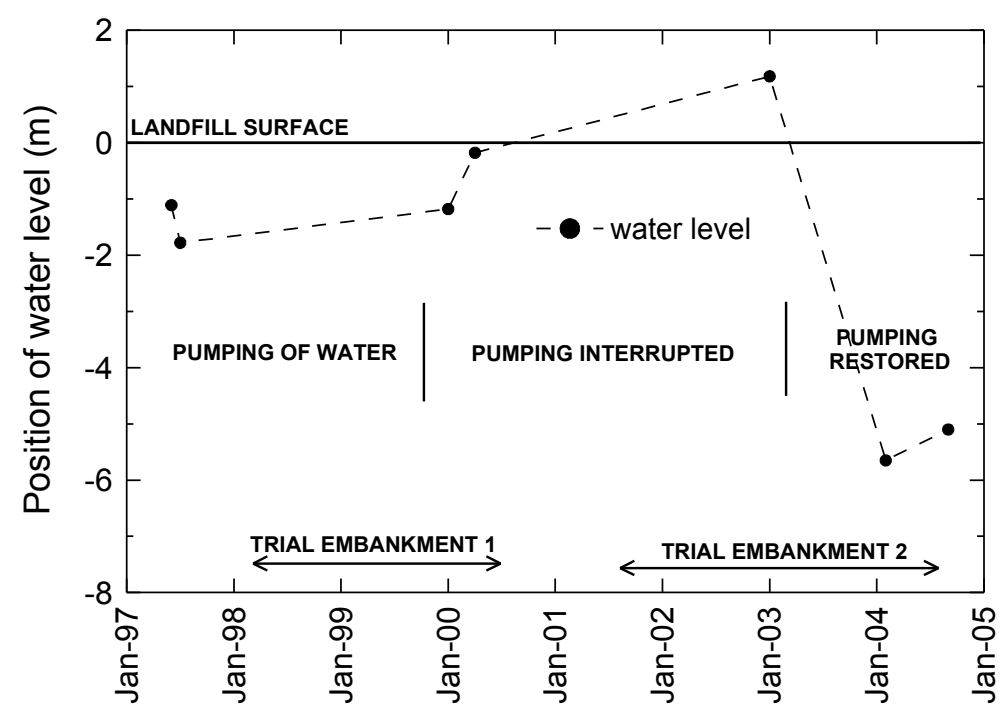

Fig. 4: Ground water level variations during the monitoring of embankments.

Due to the pumping of water from nearby fly ash lagoon, the ground water level varied during the period of the monitoring of both embankments, as shown in Fig. 4. The pumping was interrupted in the period 1999 to 2003, which resulted in a rise of water level above soil surface. After resuming the pumping in 2003, water level decreased approximately $5 \mathrm{~m}$ below the surface.

The settlement in the central axis of both embankments is presented in Fig. 5a. The fast initial settlement immediately after the construction is followed by the slower deformation in the following years. The final settlements of 0.23 and $0.58 \mathrm{~m}$ were measured under Embankments 1 and 2 , respectively. The data from the depth reference points are presented in Figs. 5b and 5c. In the case of Embankment 1 (Fig. 5b) the measurement from June 2000 is presented, because the data from the later measurements are incomplete and influenced by the heave associated with the rising water level. The intervals of measurement are shown in Fig. 4 (these intervals were also subject of the numerical modelling). The settlement of depth reference points under Embankment 2 (Fig. 5c) corresponds to the last measurement, which was carried out in September 2004. The data from the depth reference points indicate, that the affected zone below the embankments is limited to the upper 20-25 m. 


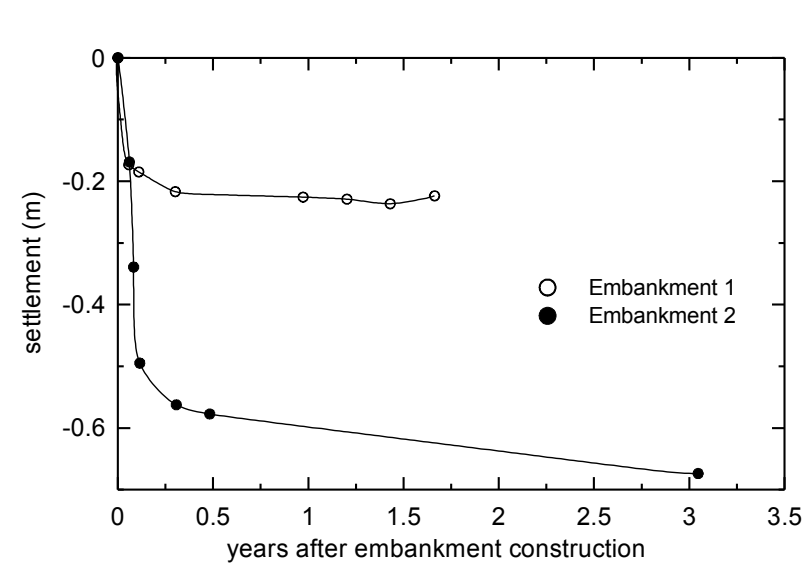

(a)

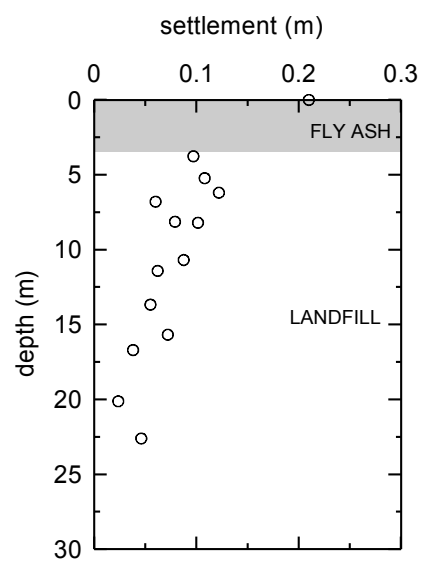

(b)

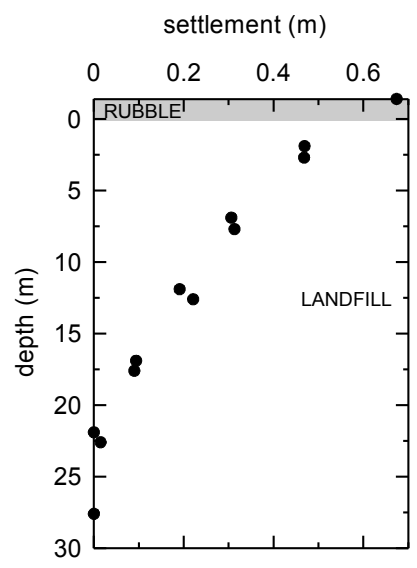

(c)

Fig. 5: Results of in situ measurement of hydrostatic levelling profiles (a) and depth reference points (Embankment 1 (b) and Embankment 2 (c)).

\section{CONSTITUTIVE MODELLING OF THE LUMPY MATERIAL}

Mašín et al. [27] and Koliji et al. [2] pointed out the relation between the mechanical behaviour of cemented and lumpy soils. Their concept was used in this paper to predict the behaviour of lumpy clay landfills. The constitutive models for cemented soil (for example, [30-35]) are based on the observation that the cementation structure allows the cemented soil to exist at higher void ratios than the reference soil at the same stress level. In terms of the critical state soil mechanics, the cementation structure increases the size of the state boundary surface (SBS) (see [33,36]). The interparticle bonding also implies a true cohesion, the SBS is thus translated into the region of tensile stresses. At certain stress level (Yield stress) the inter-particle bonds start to break, and with increasing load the size of the SBS gradually converges toward the size of the SBS of the reference soil.

In principle similar approach can be used for constitutive modelling of lumpy soils (Fig. 6). In this case, the reference model is used to predict the behaviour of clayey lumps, which have intragranular porosity only. The additional intergranular porosity due to the lumpy structure is allowed for by increasing the size of the state boundary surface (see Fig. 6). The intergranular porosity (the lumpy structure) degrades during straining of the material, and the effect on the total porosity is similar to the degradation of inter-particle bonds in cemented materials. The behaviour of lumpy soils can thus be predicted using models mathematically equivalent to the models for cemented soils. Unlike the 
cemented soil, the lumpy soil does not have a true cohesion.

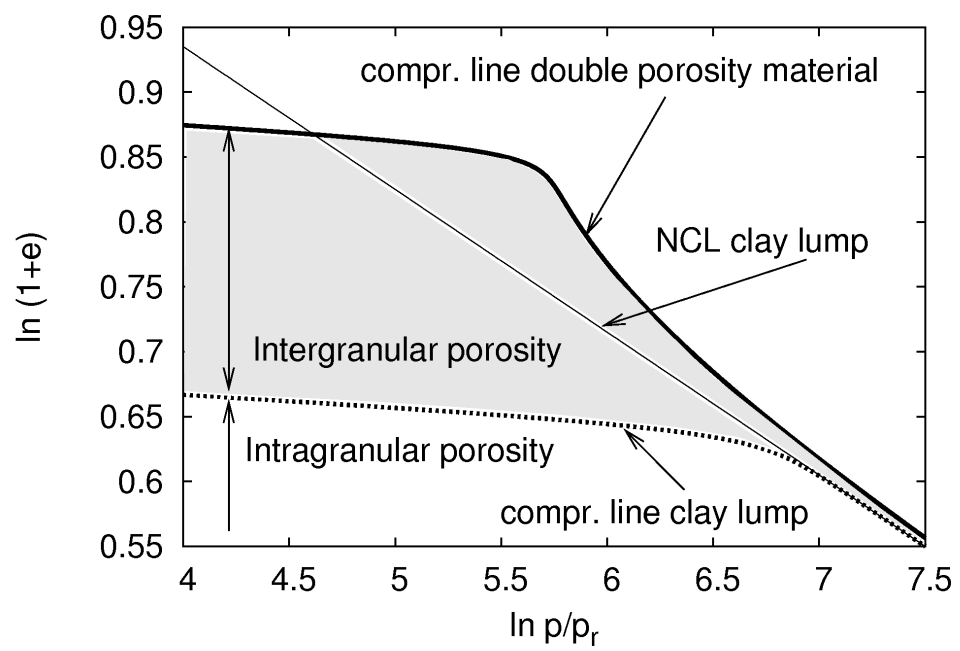

Fig. 6. Modelling framework for the behaviour of clays with lumpy structure (after Mašín et al. [27], modified).

The reference material of clay lumps is in this paper modeled using the hypoplastic model for clays by Mašín [37]. The model is based on hypoplasticity [38], an approach to constitutive modelling of soils developed independently at the Universities of Karlsruhe (Karlsruhe, Germany) and Grenoble (Grenoble, France), see Tamagnini et al. [39] for overview. The models were originally developed for the behaviour of granular materials, with probably the most popular model by von Wolffersdorff [40]. Later on, the research focused on the development of hypoplastic models for clays [37,41-43]. One of the examples is the model by Mašín [37]. The model combines the critical state soil mechanics theory, of which particular example is the Modified Cam clay model [44], with the nonlinear formulation of hypoplastic models. This model thus requires 5 parameters, whose physical interpretation of is the same as of the parameters of the Modified Cam Clay model. The parameters can easily be calibrated on the basis of standard laboratory experiments. The parameters $N$ and $\lambda^{*}$ define the position and slope of the isotropic normal compression line (NCL), $\kappa^{*}$ represents the slope of the swelling line, $\varphi_{c}$ is the critical state friction angle and the last parameter $r$ characterizes soil shear stiffness. The calibration of the model is detailed in Sec. 4. Note that the model thanks to its non-linearity does not predict constant slope of the unloading-reloading curve in the $\ln p$ vs. $\ln (1+e)$ representation, but the slope changes with OCR and loading direction (the parameter $\kappa^{*}$ specifies the slope for unloading from the isotropic normally consolidates state). For this reason, the parameter $\kappa^{*}$ is often calibrated by means of a trial-and-error procedure by simulation of the isotropic or oedometric experiments.

The basic hypoplastic model predicts successfully the soil behaviour in the medium to large strain 
range. However, in the small strain range and upon cyclic loading they fail in predicting the high quasi-elastic soil stiffness. To overcome this drawback, Niemunis and Herle [45] proposed an extension of the hypoplastic equation by considering additional state variable "intergranular strain" to determine the direction of the previous loading. This extension is, however, not adopted in the present paper, as it concerns monotonous loading processes in the large-strain range.

The basic model for clays has been later on enhanced to predict the behaviour of clays with metastable structure by Mašín [30]. This model assumes one additional state variable - sensitivity $s$, defined as a ratio of the sizes of state boundary surfaces of natural and reference materials. This state variable has been proposed and used in earlier constitutive models for structured clays by other authors, see $[33,45]$. The model requires three additional parameters, describing the rate of structure degradation $(k)$, final sensitivity $\left(s_{f}\right)$ and a parameter controlling the influence of a shear strain rate on structure degradation $(A)$. This model was used to predict the behaviour of the lumpy soil.

\section{CALIBRATION OF THE HYPOPLASTIC MODEL}

\subsection{Calibration of the basic model}

As indicated in Sec. 3, the reference material for simulation of the lumpy clay is the material of clay lumps. Therefore, in principle, the parameters of the reference hypoplastic model should be calibrated using laboratory experiments on the material of clay lumps. As the available experimental results on this material include triaxial shear tests only, which are not sufficient to calibrate all the model parameters, different approach was chosen. The model was calibrated using tests on reconstituted soil. The obtained parameter set was subsequently used in predictions of shear tests on the material of clay lumps, to indicate the two materials can be described using the same parameters.

Isotropic compression tests on reconstituted clay samples from the neighbouring " 5 . květen" landfill were used for the calibration of the model parameters $N$ and $\lambda^{*}$ (Fig. 7). The laboratory experiments were described in detail by Hájek et al. [46]. A set of triaxial tests on the reconstituted specimens from the subsoil of Embankment 2 was carried out to determine the parameters $\varphi_{c}$ and $r$. The specimens were consolidated isotropically to the required mean effective stresses $\left(p^{\prime}=100,200\right.$ and $300 \mathrm{kPa}$ respectively) and undrained triaxial shear tests were carried out. The experimental data and predictions by the model are shown in Fig. 8. 


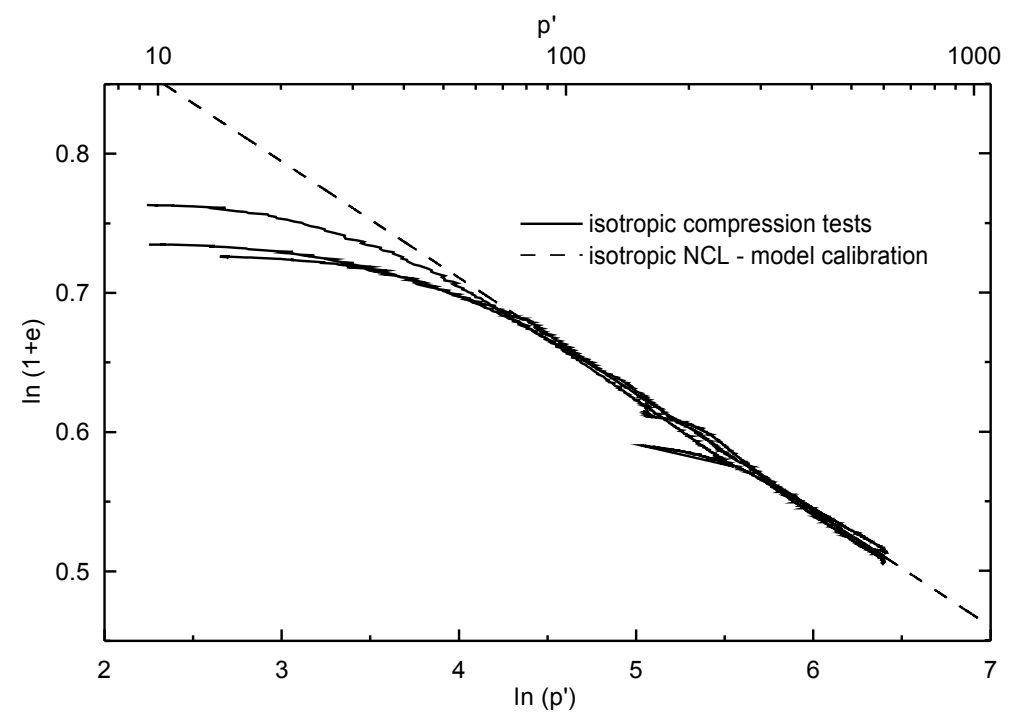

Fig. 7. Calibration of the parameters $N$ and $\lambda^{*}$ on isotropically compressed reconstituted specimens.

The last parameter, $\kappa^{*}$, influences significantly the compression curve in the low stress range and its value used in subsequent numerical simulations was determined directly from the tests on lumpy clay oedometer specimens (section 4.2). This is because the experimental data indicate that the parameter $\kappa^{*}$ depends on the value of the lumpy structure. As the dependency of $\kappa^{*}$ on structure is not incorporated in the formulation of the constitutive model, $\kappa^{*}$ was calibrated directly using tests on lumpy specimens. The obtained dependency of $\kappa^{*}$ was considered in the numerical simulations. For the calibration of other parameters using the results of tests on the reconstituted soil $\kappa^{*}=0.014$ was adopted. 


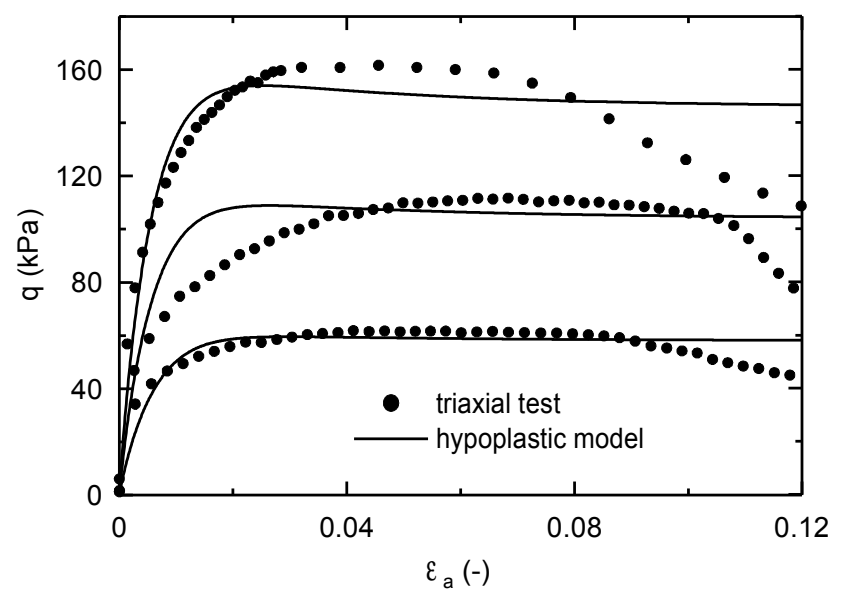

(a)

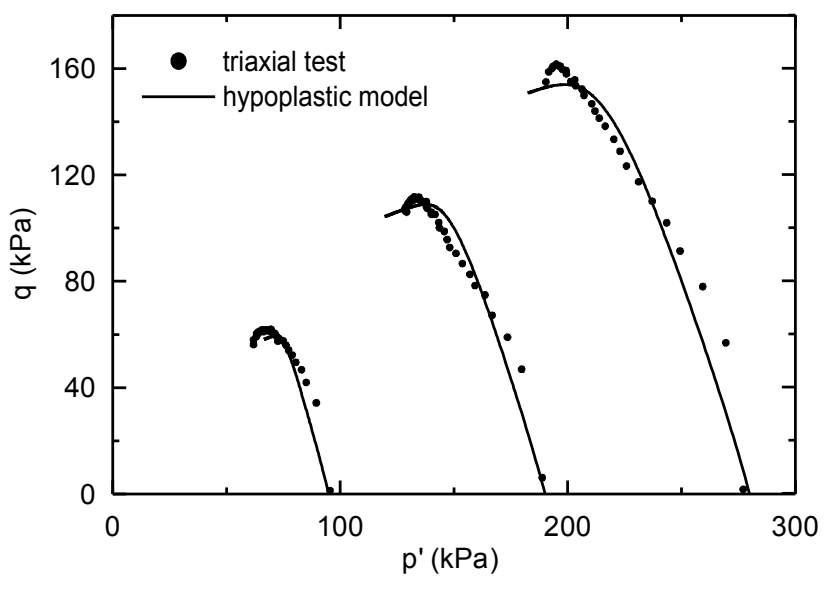

(b)

Fig. 8. Calibration of the parameters $\varphi_{c}$ and $r$ using the results of the triaxial compression tests on the reconstituted clay.

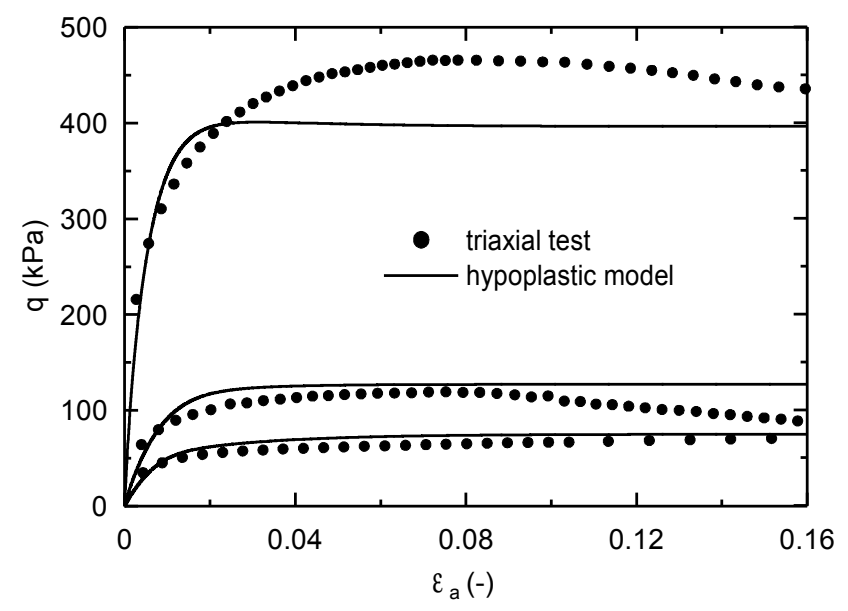

(a)

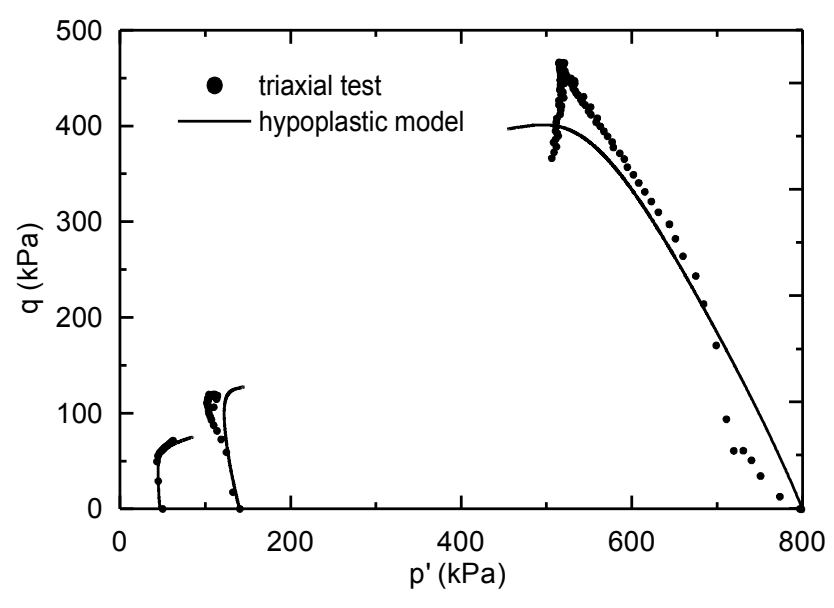

(b)

Fig. 9. Comparison of triaxial compression tests on natural landfill clay specimens and predictions of basic hypoplastic model for clays.

The performance of the hypoplastic model, calibrated using results on the reconstituted clay, was examined by simulating three triaxial compression tests on undisturbed specimens from the neighbouring landfill carried out by Herbstová et al. [47] (Fig. 9). The undisturbed specimens were obtained from the depth of the landfill where the intergranular porosity had already degraded. The behaviour of the specimens thus represents the behaviour of the reference material. Fig. 9 demonstrates good agreement between the simulated and experimental data. The parameters based on the tests on reconstituted soil can thus be considered as suitable parameters of the reference 
hypoplastic model.

\subsection{Calibration of the parameters describing the lumpy structure}

The parameters and variables controlling the effects of the lumpy structure were found using oedometer tests on the lumpy clay specimens with scaled down lump size distribution, preconsolidated in a mini-centrifuge. The clay from the landfill area was air dried at $50^{\circ} \mathrm{C}$ and crushed between two metal platens. The lumps produced were sieved and remixed to give an appropriate in situ grain size distribution with grain (lump) size scaled down by a factor of 180 (maximum lump size was $2.5 \mathrm{~mm}$ ). This technique of the preparation of scaled-down clay lumps allows to keep the similar shape of the lumps as in situ and the original fabric of the lumps is also preserved. Therefore the strength and hydraulic conductivity of the lumps (influencing the rate of the structure degradation of the soil), is expected to represent correctly the field conditions. The lumps were poured into four cylindric containers with the diameter of $80 \mathrm{~mm}$ and depth of $140 \mathrm{~mm}$ and flooded. The flooding of the landfill model after filling reflects the field conditions at a site of the trial embankments. After the saturation, the containers were placed into the mini-centrifuge and the soil was consolidated at $180 \mathrm{~g}$. The structure of the fully consolidated landfill model varied significantly with depth. The lumpy structure could still be observed in the top part of the model. In the deeper part of the model, the interlump voids mostly closed due to plastic straining at the contacts of the lumps. After the consolidation and unloading, seven oedometer specimens were prepared from different heights of the models. The specimens were installed in $71.5 \mathrm{~mm}$ diameter oedometers and compressed subsequently under one-dimensional conditions (detailed description of the mini-centrifuge and the test procedure can be found in Najser et al. [48]).

In simulating the oedometric tests on the lumpy soil, the value of $p^{\prime}$ was calculated using $K_{0}=0.62$ obtained from Jaky's formula $K_{0}=1-\sin \varphi_{c}$. When all intergranular voids close, the compression line of the lumpy clay specimens according to the framework set up in Sec. 3 joins the NCL of the reference soil. The required vertical stress for the complete degradation of the lumpy structure was not reached before the end of the oedometric tests (Fig. 10). However, the results indicate that at higher stresses the compression line of the lumpy specimens converges towards the NCL of the reference soil (it was experimentally confirmed by Henriquez [49]), and the value of $s_{f}=1$ was therefore used. The oedometer test on intact clay (material of the clay lump) carried out by Henriquez [49] is also presented in Fig. 10, to indicate that the reconstituted soil and clay lump material follow the same NCL (supporting conclusions from Sec. 4.1). 


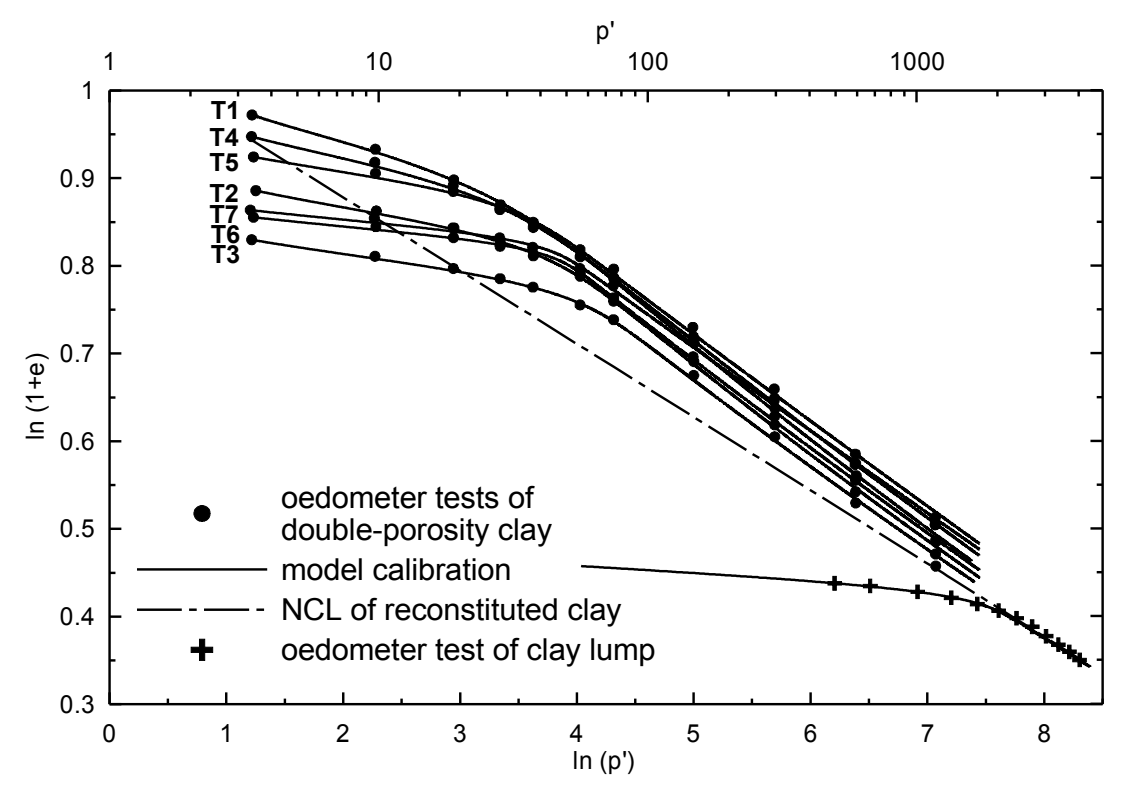

Fig. 10. Calibration of the soil structure from the oedometer tests on lumpy clay. Experimental data on clay lump from Henriquez [49].

As no shear tests on the lumpy clay material were performed, a reasonable value of the parameter $A$ was assumed based on the behaviour of natural structured clays $(A=0.25)$ [30]. The parameter $k$, the initial value of structure $s_{0}$ and the basic model parameter $\kappa^{*}$, which influence the slope of the compression curve before reaching NCL, were calibrated separately for each oedometer lumpy specimen (Fig. 10). Table 1 summarizes the corresponding values of $k, \kappa^{*}$ and $s_{0}$ together with maximum $\sigma_{v}{ }^{\prime}$ reached during preconsolidation of the soil in mini-centrifuge before the oedometer tests. When plotted against $\sigma_{v}{ }^{\prime}$ reached in the mini-centrifuge (Fig. 11), it is evident that the parameter $\kappa^{*}$ and the value of $s_{0}$ depend on the pre-consolidation vertical stress and consequently on the initial void ratio of the oedometer specimens. No trend in stress dependency was found for the parameter $k$, so value of $k=0.28$ was considered as an average value from all tests. 


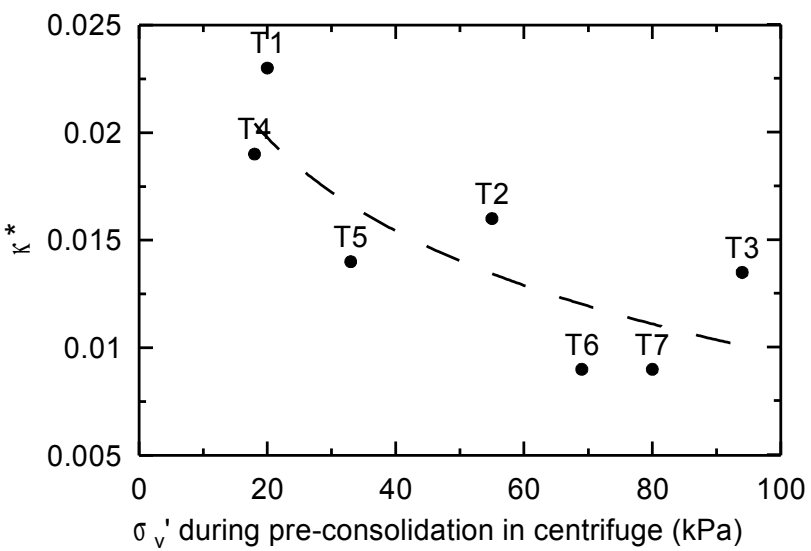

(a)

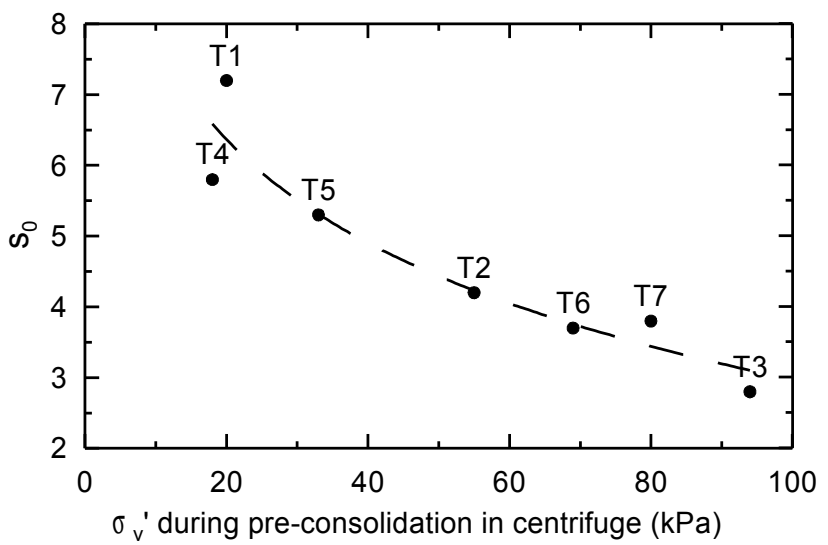

(c)

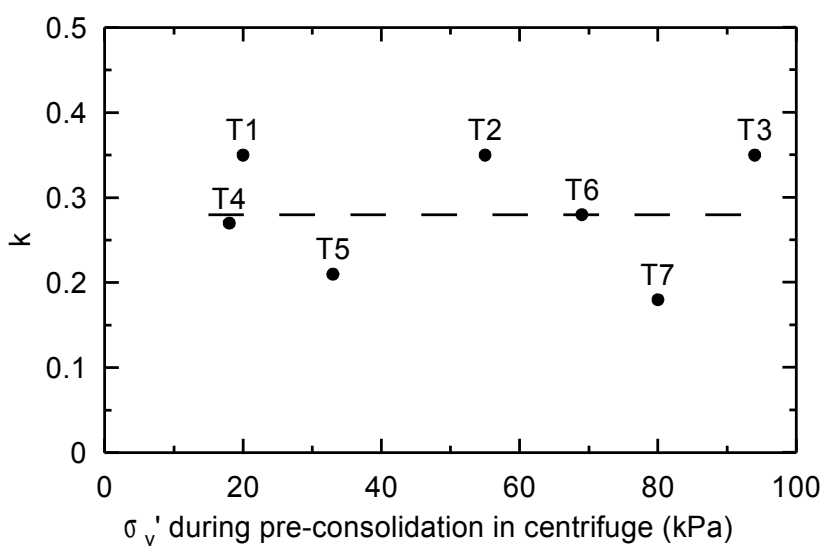

(b)

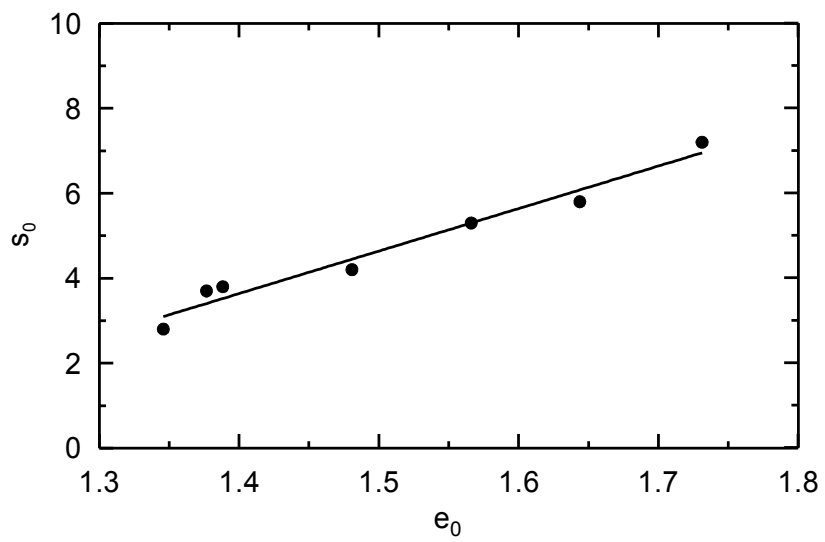

(d)

Fig. 11: The dependency of $\kappa^{*}, k$ and $s_{0}(a, b, c)$ on preconsolidation stress applied to oedometer specimens in the mini-centrifuge. The dependency of $s_{0}$ on $e_{0}(d)$.

\begin{tabular}{|c|c|c|c|c|c|}
\hline Oedometer test & $\sigma_{v}{ }^{\prime}$ in centrifuge $(\mathrm{kPa})$ & $\kappa^{*}$ & $k$ & $s_{0}$ & $e_{0}$ \\
\hline $\mathrm{T} 1$ & 20 & 0.023 & 0.35 & 7.2 & 1.73 \\
\hline $\mathrm{T} 2$ & 55 & 0.016 & 0.35 & 4.2 & 1.48 \\
\hline $\mathrm{T} 3$ & 94 & 0.0135 & 0.35 & 2.8 & 1.35 \\
\hline $\mathrm{T} 4$ & 18 & 0.019 & 0.27 & 5.8 & 1.64 \\
\hline $\mathrm{T} 5$ & 33 & 0.014 & 0.21 & 5.3 & 1.57 \\
\hline $\mathrm{T} 6$ & 69 & 0.009 & 0.28 & 3.7 & 1.38 \\
\hline $\mathrm{T} 7$ & 80 & 0.009 & 0.18 & 3.8 & 1.39 \\
\hline
\end{tabular}

Tab. 1. Data from calibration of the soil structure parameters on oedometer specimens. 
For the stress dependent parameter $\kappa^{*}$ it was taken into account that the initial conditions for the centrifuge modelling should represent the loosest state of the landfill before the self-weight consolidation takes place. Therefore $\kappa^{*}=0.0187$ used in the predictions of the self-weight consolidation stage and for embankment loading stage was chosen as the mean value of three loosest oedometer specimens.

The dependency on vertical stress was found also for the initial sensitivity $s_{0}$. This finding is obvious, as increasing the vertical stress during preconsolidation in mini-centrifuge causes according to the framework from Sec. 3 a degradation of the soil structure. Even small change in $s_{0}$ significantly influences the predictions of the landfill settlement, because it influences the apparent preconsolidation stress. At higher stresses, the structure degrades and the soil has large compressibility, whereas at lower stresses the structure is stable and the soil response is relatively stiff, controlled by the parameter $\kappa^{*}$. The dependency of $s_{0}$ on $e_{0}$ was therefore considered in the analyses. A linear relationship represents appropriately the experimental data (Fig. 11d):

$$
s_{0}=10.35 \cdot e_{0}-10.87
$$

Summary of the parameters of the hypoplastic model for structured clays is given in Tab. 2 .

\begin{tabular}{|c|c|c|c|c||c|c|c|}
\hline$\varphi_{c}$ & $\lambda^{*}$ & $\kappa^{*}$ & $N$ & $r$ & $k$ & $A$ & $S_{f}$ \\
\hline 22.4 & 0.0835 & 0.0187 & 1.045 & 0.3 & 0.28 & 0.25 & 1 \\
\hline
\end{tabular}

Tab. 2. Parameters of the hypoplastic model for clays with meta-stable structure.

\section{MODELLING OF CENTRIFUGE TESTS}

\subsection{Centrifuge tests}

The centrifuge modelling of the case history of Embankment 2 was carried out in the geotechnical drum centrifuge at ETH Zürich in Switzerland. A detailed description of the centrifuge can be found in Springman et al. [50]. The centrifuge models were prepared in square containers (400 x $400 \mathrm{~mm}$ in plan, $200 \mathrm{~mm}$ height) using NW Bohemian landfill clay. Clay lumps were air dried, crushed and sieved to obtain the scaled-down lump size distribution equivalent to the field (dimensions of the lumps were reduced according to the centrifuge scaling laws [51]). As explained in Sec. 4.2, it is 
believed that the model material represents appropriately the behaviour of the lumpy soil of the landfill. The centrifuge modelling was carried out at the nominal g level of 150 measured at an effective radius of $0.91 \mathrm{~m}$. The centrifuge models were fully saturated before the test and the water level was kept constant close to the model surface during the test. After the end of the self-weight consolidation, the centrifuge was stopped, a geotextile was placed on the landfill surface and a 2D embankment was constructed from sand (rubble stone layer was neglected in the centrifuge modelling). The embankment was $7.5 \mathrm{~m}$ high (in the prototype scale) with the length of the embankment crest corresponding to $13.5 \mathrm{~m}$ and length of the ramp $20.5 \mathrm{~m}$. After reacceleration to $150 \mathrm{~g}$, the model was monitored until the consolidaton below the embankment was completed. The same monitoring as in situ was carried out including measurement of surface settlement and the settlement of the depth reference points by laser. Details about the centrifuge test, model preparation and instrumentation are beyond the scope of this paper and can be found, e.g., in Najser et al. [52].

\subsection{Numerical modelling}

The model parameters from Tab. 2 were used in the numerical simulation of the centrifuge test. The modelling was performed using finite element method in 2D using the software package Tochnog Professional [53]. The constitutive model was implemented using a user-defined subroutine, which is freely available on the internet (Gudehus et al. [54]). An explicit adaptive integration scheme with local substepping based on the Runge-Kutta-Fehlberg method of the 3-rd order of accuracy (RKF23) was used for the time integration of the constitutive model. A fully coupled consolidation analysis was carried out. However, as indicated in the Introduction, the main aim of the research was to predict the mechanical response of the lumpy clay material, rather then the consolidation characteristics of a double-porosity medium. For this reason, consolidation of the landfill was treated in a simple way. The hydraulic conductivity linearly dependent on the stress level was chosen for the numerical modelling based on the back analysis of the rate of consolidation in the centrifuge models $\left(5^{*} 10^{-8} \mathrm{~m} / \mathrm{s}\right.$ at $\sigma_{v}{ }^{\prime}=5 \mathrm{kPa}$ and $1^{*} 10^{-10} \mathrm{~m} / \mathrm{s}$ at $\left.\sigma_{v}{ }^{\prime}=150 \mathrm{kPa}\right)$.

The initial void ratio $e_{0}=1.78$ was used based on the centrifuge test and the initial sensitivity $s_{0}=7.54$ was calculated from Eq. (2). The unit weight of the landfill $\gamma=16.1 \mathrm{kN} / \mathrm{m}^{3}$ was determined from the average density of the lumpy clay before the centrifuge test. The embankment body was modelled using the Mohr-Coulomb model (Tab. 3). The results of modelling of the selfweight consolidation presented in Fig. 12 show good correlation with the experimental data from the centrifuge test. 


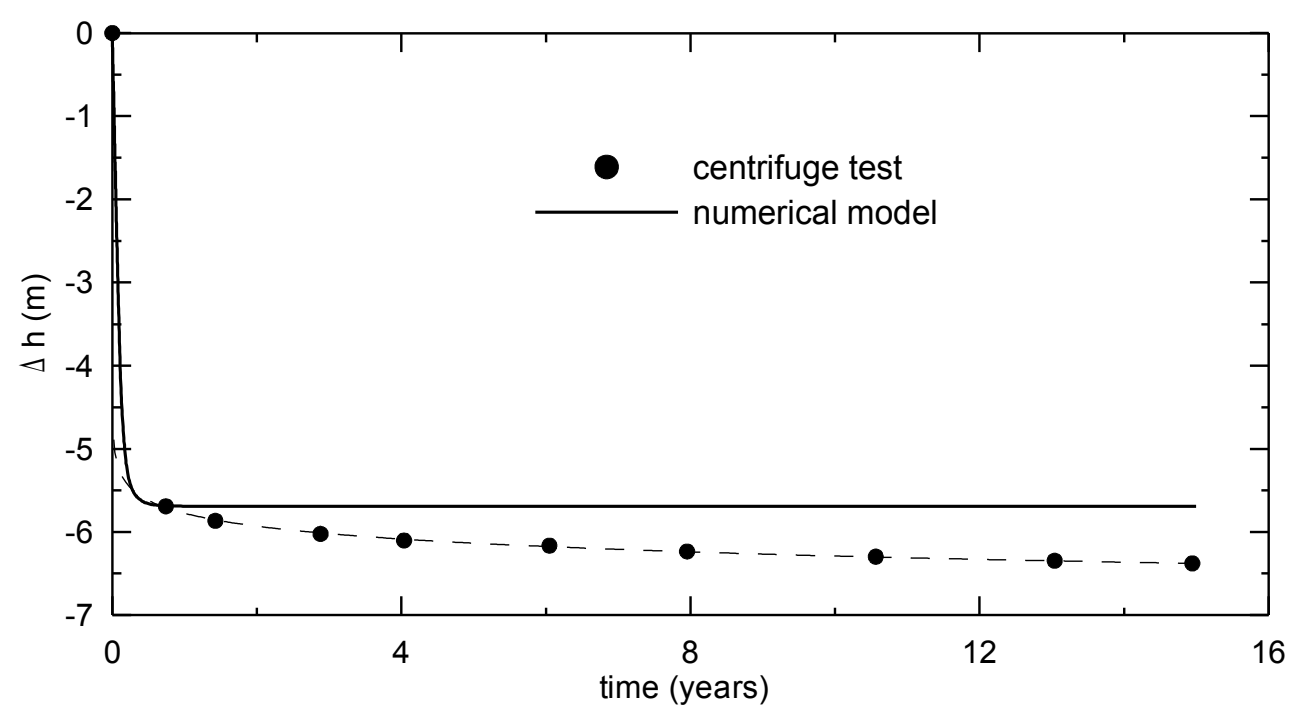

Fig. 12. Comparison of self-weight consolidation of centrifuge and numerical model of the landfill.

\begin{tabular}{|l|c|c|c|c|c|c|c|}
\hline & Case history & $\mathrm{E}(\mathrm{MPa})$ & $v(-)$ & $\varphi^{\prime}\left(^{\circ}\right)$ & $\mathrm{c}^{\prime}(\mathrm{kPa})$ & $\psi\left({ }^{\circ}\right)$ & $\gamma\left(\mathrm{kN} / \mathrm{m}^{3}\right)$ \\
\hline Embankment & centrifuge test & 25 & 0.25 & 40 & 1 & 20 & 30.12 .1899 \\
\hline Embankment & Emb.1, Emb. 2 & 15 & 0.4 & 27 & 1 & 13.5 & 17.6 \\
\hline Fly ash & Emb. 1 & 3.5 & 0.35 & 35 & 1 & 17.5 & 15.9 \\
\hline Rubble stone & Emb. 2 & 25 & 0.25 & 40 & 1 & 17 & 19 \\
\hline
\end{tabular}

Tab. 3. Mohr-Coulomb parameters and unit weights of materials considered in simulations.

The surface settlements of the centrifuge and numerical models after the embankment surcharge are compared in Fig. 13a. The geotextile below the embankment was modelled as truss elements without interface elements (thickness of $0.1 \mathrm{~m}, E=25 \mathrm{GPa}$ ). The comparison shows $20 \%$ smaller settlement of the centrifuge model (the final settlement in prototype scale $1.6 \mathrm{~m}$ ) as compared to numerical model (the final settlement $2 \mathrm{~m}$ ).

The settlement of the landfill in the vertical profile is presented in Fig. 13b. Due to the incomplete data of the depth reference points in the centrifuge, the final values could not be plotted and the time of the measurement in Fig. 13b corresponds to 656 days (in prototype scale) after the embankment construction. It shows that the difference between the centrifuge and numerical model gradually increases over the whole vertical profile. In general, however, it may be concluded that the predictions of the centrifuge tests are in a reasonable agreement with the centrifuge test results. 


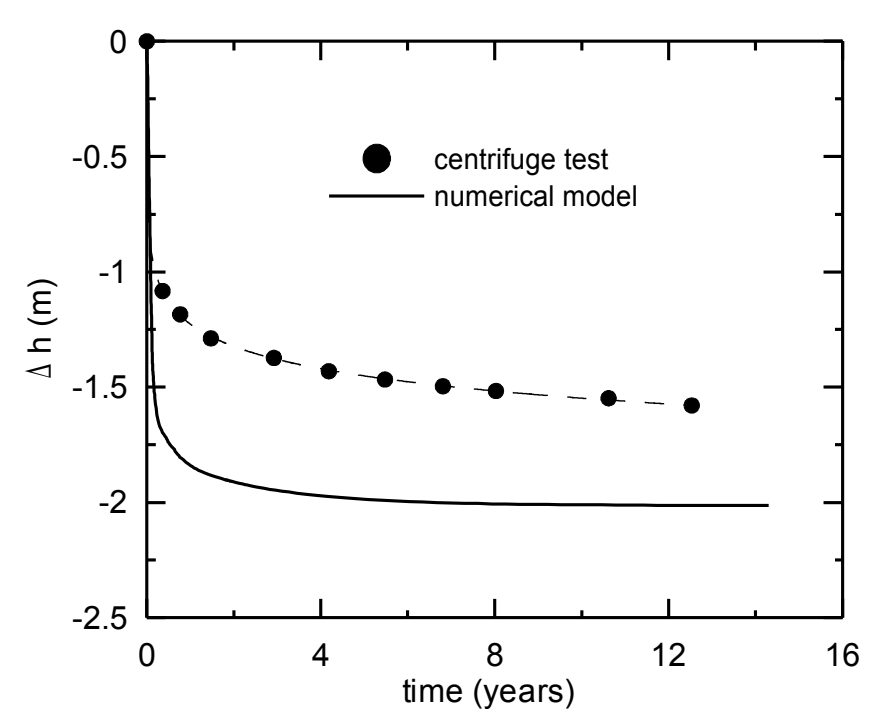

(a)

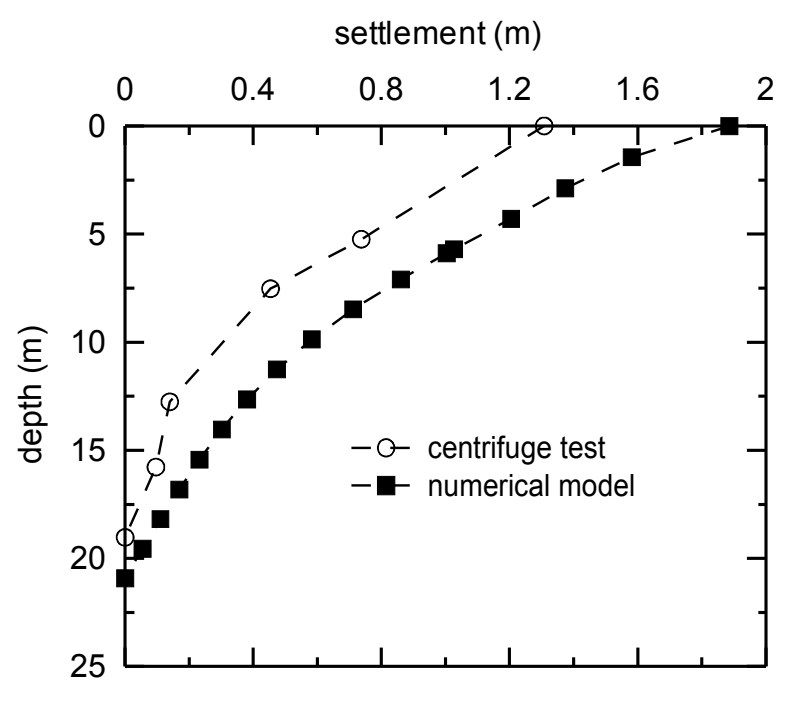

(b)

Fig. 13. Comparison of the centrifuge and numerical modelling of the settlement under Embankment 2.

\section{MODELLING OF TRIAL EMBANKMENTS}

The two field trial embankments were simulated using finite element method under plane strain conditions. As in the case of the modelling of centrifuge test, fully coupled consolidation analyses were used.

\subsection{Embankment 1}

The pluviation of the $3.5 \mathrm{~m}$ fly ash layer mixed with a rubble stone on the top of the landfill was simulated by gradual increase of its unit weight between 15 to 20 years after the landfill construction. The unit weight of the landfill of $\gamma=16.1 \mathrm{kN} / \mathrm{m}^{3}$ was used for the modelling of both case histories. Unit weights of other materials are indicated in Tab. 3. The construction of the embankment started 25 years after the landfill construction and took 45 days. The geometry of the model and the finite element mesh are presented in Fig. 14.

The embankment body and fly ash layer were modelled using the Mohr-Coulomb model (the parameters are summarized in Tab. 3.). The initial values of void ratio $e_{0}=1.78$ and $s_{0}=7.54$ obtained from the centrifuge model were used to represent the initial conditions for the landfill as there were no available data about the initial porosity from the field. 
During filling in situ, no water was present in the mine pit as a result of pumping of water during mining. The landfill was flooded later by a gradual increase of ground water level between 3 to 10 years after landfill construction. Finally, the groundwater level reached the landfill surface. In the numerical model, a gradual rise of water level after filling was simulated by a decrease of the effective unit weight of the landfill.

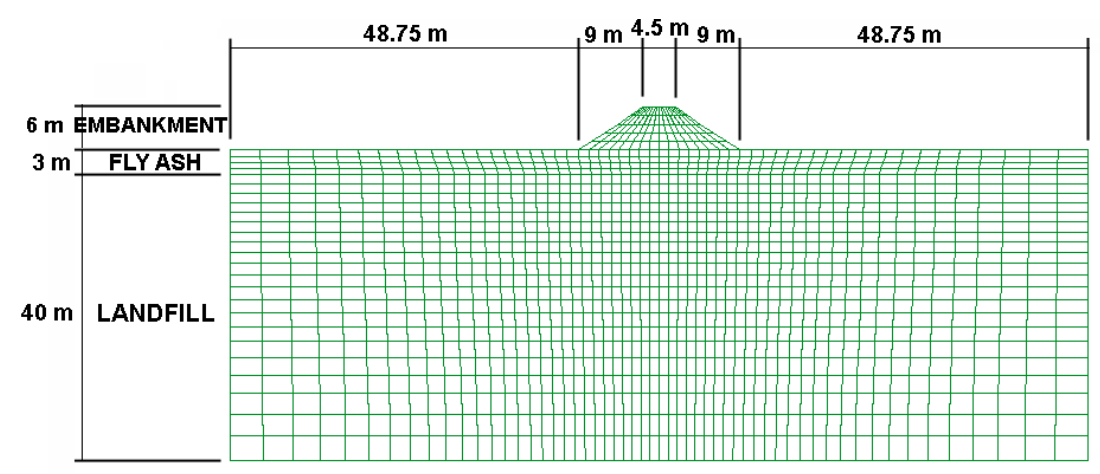

Fig. 14. Geometry and finite element mesh of numerical model of Embankment 1.

\subsection{Embankment 2}

The geometry of the model and the finite element mesh of Embankment 2 are presented in Fig. 15. No fly ash was pluviated in the location of Embankment 2. After the rise of the ground water level, the consolidation continued for another 15 years until the total time of self-weight consolidation of 25 years was reached. Then the layer of the rubble stone was placed on the top of the landfill (thickness $1.4 \mathrm{~m}$ ) and the embankment was constructed in 45 days. The decrease of the water level in the interval $1.6-2.2$ years after the embankment construction (Fig. 4) was simulated by the increase of the effective unit weight of the landfill in the top 5 metres. The parameters for the modelling of the embankment and rubble stone are presented in Table 3. The parameters for the hypoplastic model of the landfill were identical to those used in modelling Embankment 1. 


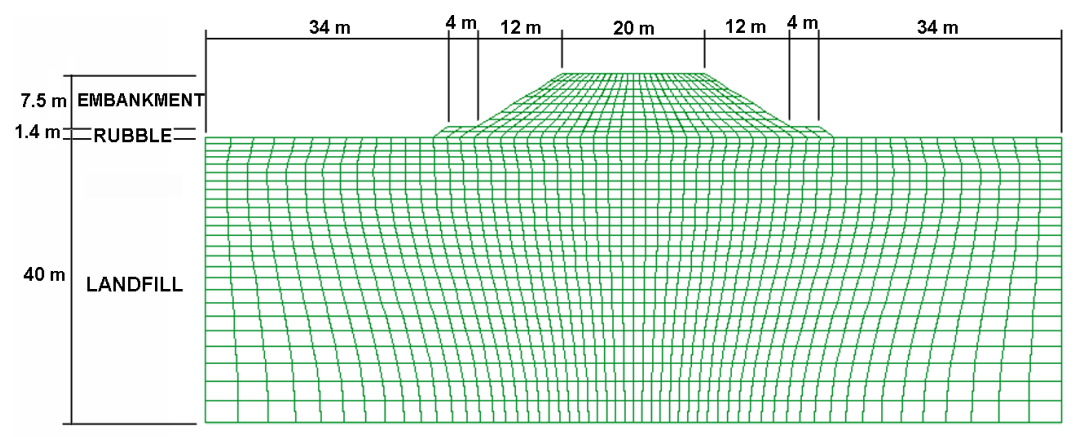

Fig. 15. Geometry and finite element mesh of numerical model of Embankment 2.

\subsection{Self-weight consolidation}

The settlement of the landfill surface at the site of Embankment 1 determined from the numerical modelling is presented in Fig. 16. The end of filling is marked by " $\mathrm{A}$ " with the settlement of $8.6 \mathrm{~m}$. The final settlement due to the self-weight consolidation was reached after approximately 2 years. The gradual increase of ground water level between 3 to 10 years after starting the filling (marked by " $\mathrm{B}$ " and " $\mathrm{C}$ ") resulted in the heave of $0.33 \mathrm{~m}$ due to the decrease of $\sigma_{v}$ '. The surcharge due to the pluviation of the fly ash (15 - 20 years, marked by " $\mathrm{D}$ " and " $\mathrm{E}^{\circ)}$ ) resulted in $0.12 \mathrm{~m}$ additional settlement (fly ash layer generated a surcharge of ${\sigma_{v}}{ }^{\prime}=18 \mathrm{kPa}$ ). No field measurements are available for comparison with the numerical simulations of the self-weight consolidation.

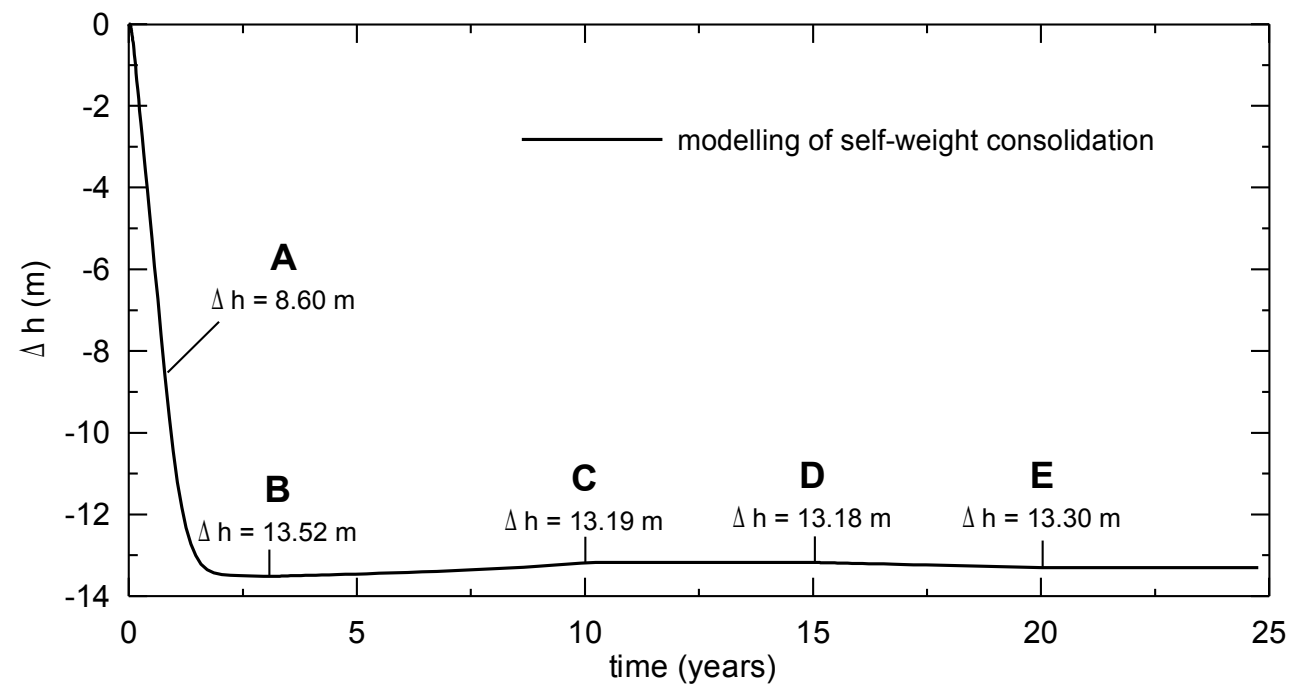

Fig. 16. Self-weight consolidation of the landfill in location of Embankment 1. 


\subsection{Settlement after embankment surcharge}

The numerical modelling showed a significantly higher settlement after the construction of both the embankments when compared to the field data (Fig 17). The calculated settlements were 3.7 and 4.4 times higher for Embankments 1 and 2, respectively. In the case of Embankment 2, the decrease of the water level during the monitoring (Fig. 4) was simulated by the increase of the effective unit weight of the landfill in the top 5 metres in the interval $1.6-2.2$ years after the embankment construction.

One of the possible reasons of the discrepancy in the final settlements is the destructuration of the landfill in shallow depth caused by weathering. In situ, the top layer is exposed to rainfall and wetting-drying cycles. The lumps are decomposed and macrovoids are partially filled with clay, which results in a lower compressibility. This hypothesis was also supported by the significantly higher settlement measured in the centrifuge model when compared to the case history (Figs. 5 and 13). In the centrifuge no weathering took place and the compressibility of the landfill model after the self-weight consolidation remained higher.

The structure degradation in shallow depth due to weathering (termed as "weathering destructuration" in the following text) was simulated by an inverse analysis of the settlement data (hydrostatic levelling profiles, depth reference points) from in situ monitoring. The calibration of the model based on the oedometer specimens with different degree of structure degradation (Fig. 10) revealed that the degree of destructuration can be described by a continuous change in the void ratio, sensitivity (Fig. 11d, Eq. (2)) and model parameter $\kappa^{*}$, which is influencing the initial slope of the compression curves (Fig. 11a). 


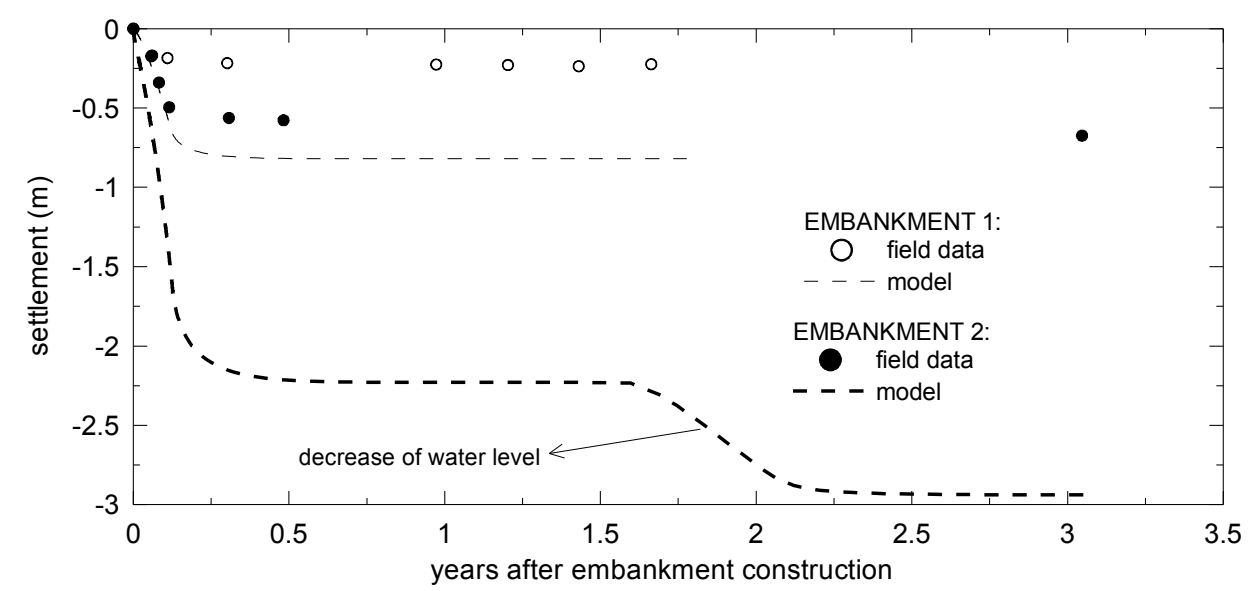

(a)

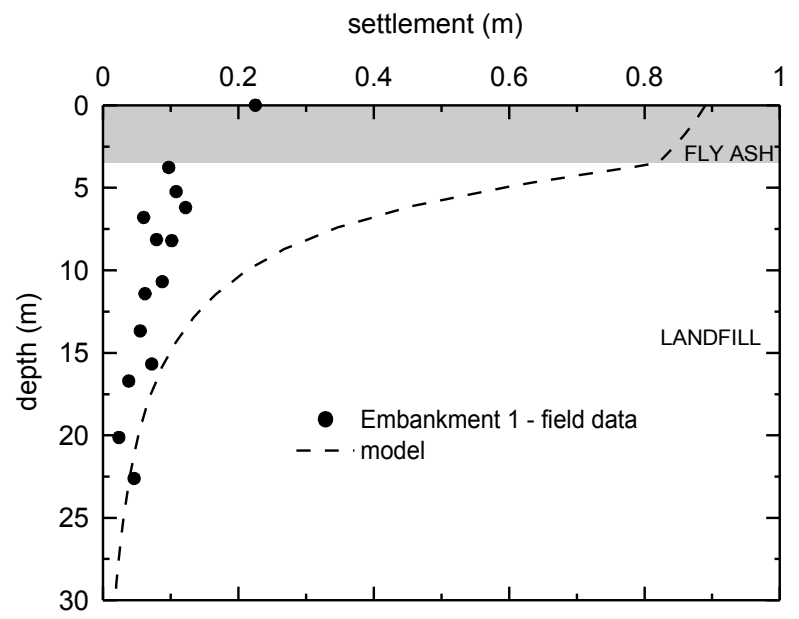

(b)

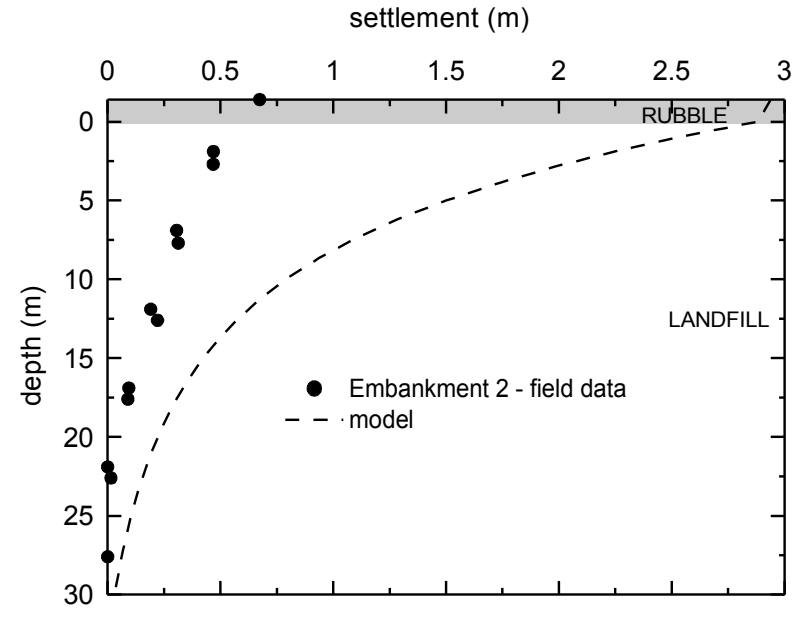

(c)

Fig. 17. Numerical modelling of the settlement under both embankments (no destructuration due to weathering).

Weathering destructuration was included in the model by reducing the void ratio at the time of 15 years after landfill construction. Sensitivity $s$ and the parameter $\kappa^{*}$ were calculated from the reduced $e$ as follows: the value of sensitivity depends both on $e$ (Eq. (2)) and $\sigma_{v}{ }^{\prime}$ (it decreases with increasing $\sigma_{v}{ }^{\prime}$ as the structure degradation proceeds). The value of $s$ can thus be specified for the given void ratio and depth in the landfill. The parameter $\kappa^{*}$ was found to decrease with the degradation of the landfill structure (Fig. 11a). The best fit curve within the measured range of $e_{0}$ was used to determine $\kappa^{*}$ after weathering destructuration (Fig. 18a),

$$
\kappa^{*}=\exp \left(\frac{e_{0}-3.62}{0.354}\right)
$$

where $e_{0}$ is found for given $e$ and $p$ in such a way that the current state lies on one of the 
corresponding compression curves from Fig. 18b. Eq. (3) is used to calculate $\kappa^{*}$ in the range of $e_{0}=1.73-1.35$, while the values of $\kappa^{*}=0.008$ (determined for the material of the clay lump by Henriquez [49] - Fig. 10) and 0.023 (maximum $\kappa^{*}$ determined for the lumpy specimens) were used outside this range. Fig. $18 \mathrm{~b}$ shows the $K_{0}$ compression curves representing the landfill with different degrees of destructuration in the whole vertical profile of the landfill with modified values of $e, s$ and $\kappa^{*}$. The destructuration of $0 \%$ corresponds to the landfill with no effect of weathering, $100 \%$ destructuration represents the overconsolidated material of the lump with no intergranular porosity. $K_{0}$ compression test carried out by Henriquez [49] was used to define the position of its compression line, see Fig. 10. The percentage of the destructuration $D_{s}$ can be defined as

$$
D_{s}=\frac{e_{s 100}-e}{e_{s 100}-e_{s 0}}
$$

where $e_{s 100}$ refers to the void ratio of fully structured model and $e_{s 0}$ refers to the void ratio of the model without the lumpy structure at the corresponding depth.

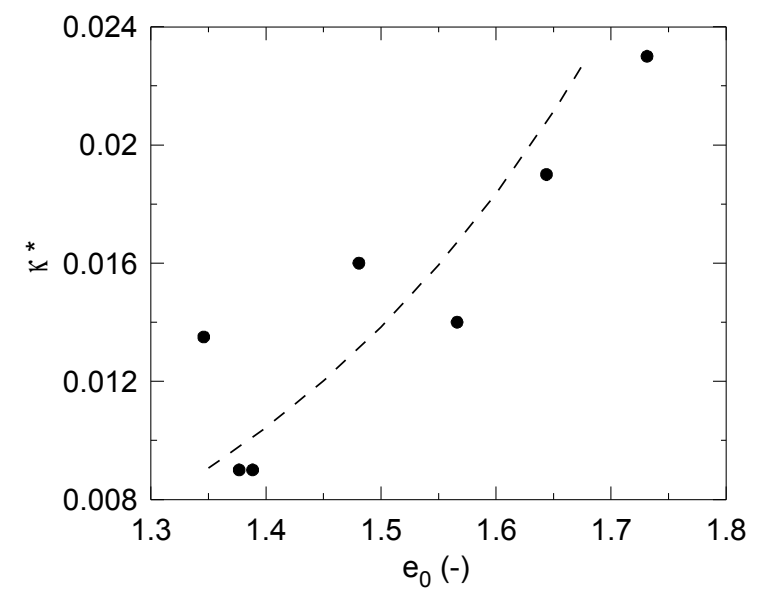

(a)

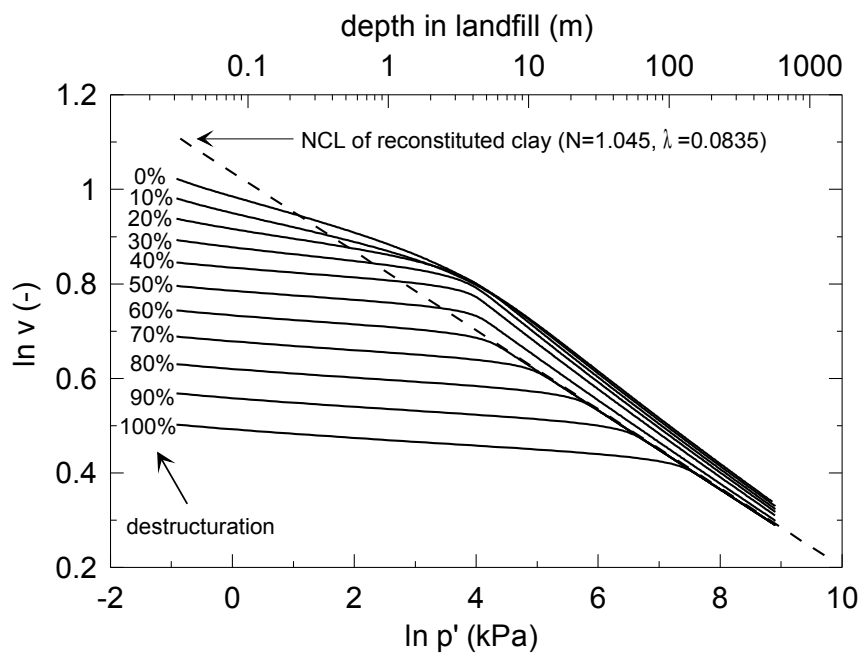

(b)

Fig. 18. Change of $\kappa^{*}$ with different $e_{0}$ based on oedometer test results (a); $K_{0}$ compression curves of lumpy clay with different degree of destructuration (b).

The inverse analyses were performed by means of a trial-and-error procedure. The $e, s$ and $\kappa^{*}$ were varied until the numerical models of both embankments predicted the same settlement profile with depth as measured in situ. The results are presented by full lines in Fig. 19. The settlement profile is well predicted by the modified model. Figures $19 \mathrm{~b}$ and $19 \mathrm{c}$ show that most of the difference between the models with an without weathering destructuration took place in the top 10 metres of the landfill. This can be expected due to the bigger influence of the weathering near the surface, and 
also because the intergranular porosity had already degraded in larger depths due to the higher stresses.

The dependency of void ratio on mean stress after destructuration can be seen in Fig. 20a. It presents the landfill state before weathering destructuration and the states of both numerical models after weathering destructuration. The compression curves from Fig. $18 \mathrm{~b}$ representing $0 \%$ and $100 \%$ destructuration are added to visualize the magnitude of the destructuration used in both case histories.

The change of destructuration with depth calculated according to Eq. (4) is presented in Fig. 20b. Different values of weathering destructuration were found under the embankments (Fig. 20). It can be assumed that the effect of weathering was similar at both sites and the difference can be attributed to different lump size distributions, or other local inhomogeneities. 


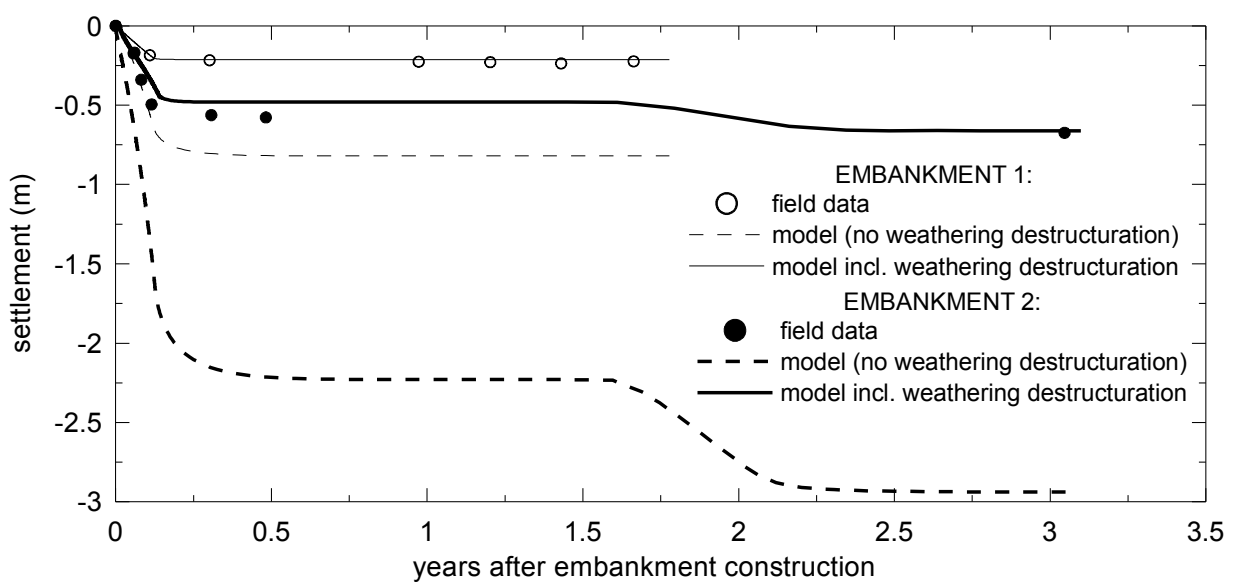

(a)

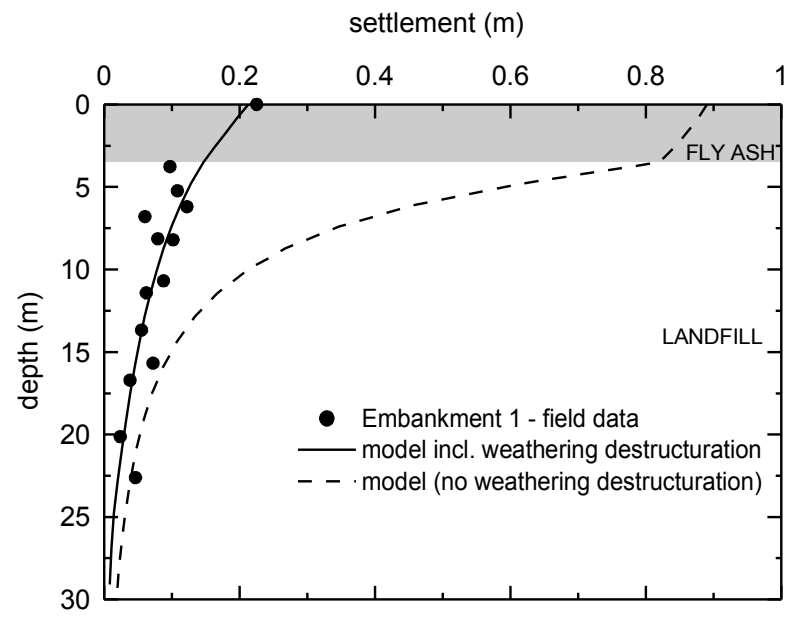

(b)

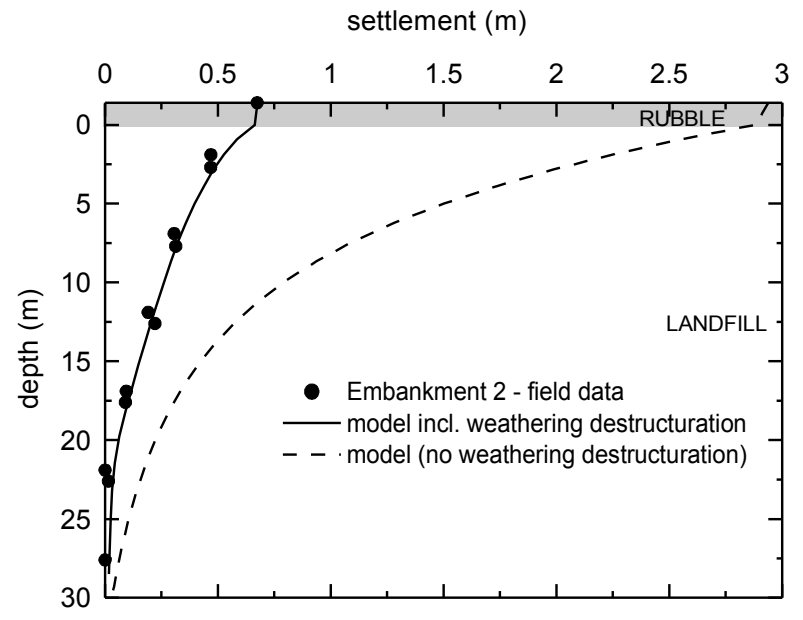

(c)

Fig. 19. Influence of weathering destructuration on the settlement. 


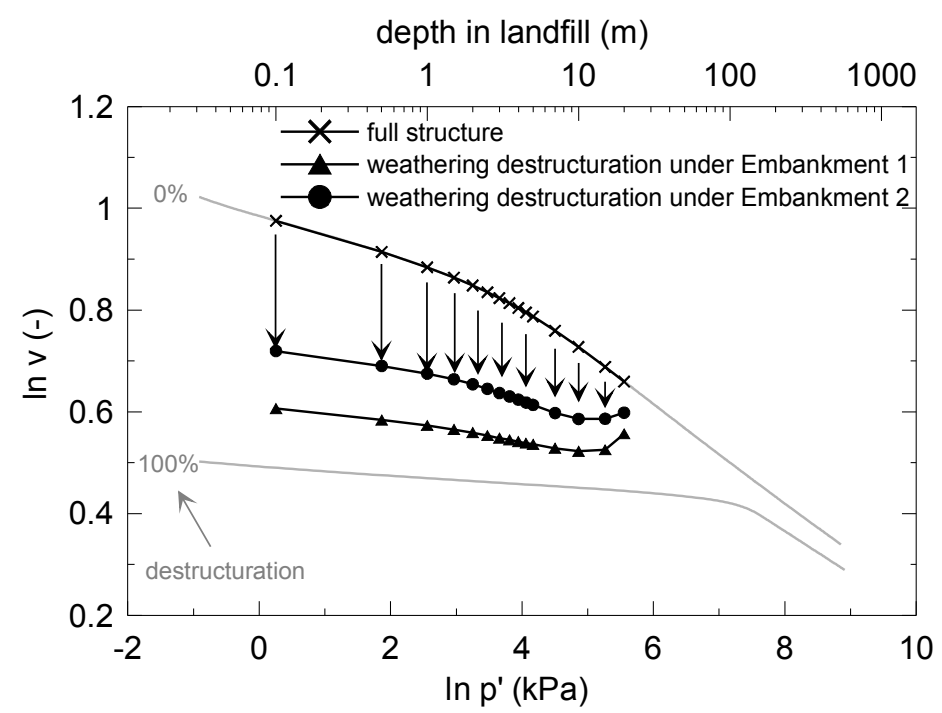

(a)

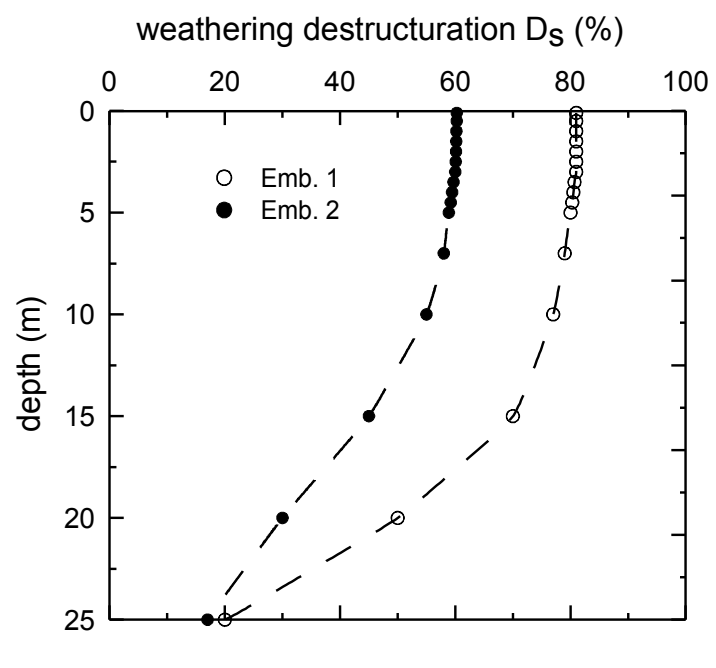

(b)

Fig. 20. Weathering destructuration under both embankments.

\section{CONCLUSIONS}

A hypoplastic constitutive model for clays with meta-stable structure was used for modelling of settlements due to embankments on lumpy clay landfills. A scaled down model from the geotechnical centrifuge showed a good agreement with the experimental results and demonstrated a good performance of the chosen constitutive model. The numerical model of the full-scale field trial embankments yielded bigger settlements due to embankment surcharge than the field measurements. Degradation of the lumpy structure in situ due to weathering in the top part of the landfill was considered as the main reason for this discrepancy. The weathering effects were modelled by reduction of the void ratio, sensitivity and parameter $\kappa^{*}$ in the vertical profile of landfill. Inverse analysis of the weathering destructuration showed that the lumpy structure is degraded in top $10 \mathrm{~m}$ and the effect of the weathering destructuration decreases with depth. The enhanced model represents well the observed settlements.

\section{ACKNOWLEDGEMENTS}

The authors greatly appreciate finantial support of the research grants GACR 205/08/0732, GACR 103/07/0678 and MSM0021620855. The part of the experimental work was carried out at ETH Zürich. The authors wish to thank Prof. S. Springman Dr. J. Laue and E. Pooley for their support. 


\section{REFERENCES}

1. Feda J (1998). Fragmentary clay - a difficult waste material. Engineering Geology 51:7788.

2. Koliji A, Vulliet L, Laloui L. (2008) New basis for the constitutive modelling of aggregated soils. Acta Geotechnica; 3(1), 61-69.

3. Lloret, A., Villar, M. V., Sanchez, M., Gens, A., Pintado, X. and Alonso, E. E. (2003). Mechanical behaviour of heavily compacted bentonite under high suction changes. Géotechnique 53, No. 1, 27-40.

4. Alonso, E. E., Lloret, A., Gens, A. and Yang, D. Q. (1995). Experimental behaviour of highly expansive double-structure clay. In Proc. of the $1^{\text {st }}$ International Conference of Unsaturated Soils, Paris, Alonso and Delage (eds.), vol. 1, 11-16.

5. Bagherieh, A. R., Khalili, N., Habibagahi, G. and Ghahramani, A. (2009). Drying response and effective stress in a double porosity aggregated soil. Engineering Geology 105, No. 1-2, 44-50.

6. Alonso, E. E., Vaunat, J. and Gens, A. (1999). Modelling the mechanical behaviour of expansive clays. Engineering Geology 54, 173-183.

7. Romero, E., Gens, A. and Lloret, A. (1999). Water permeability, water retention and microstructure of unsaturated compacted Boom clay. Engineering Geology 54, 117-127.

8. Thom, R., Sivakumar, R., Sivakumar, V., Murray, E. J. and Mackinnon, P. (2007). Pore size distribution of unsaturated kaolin: the initial states and final states following saturation. Géotechnique 57, No. 5. 469-474.

9. Khalili, N., Witt, R., Laloui, L., Vulliet, L. And Koliji, A. (2005). Effective srtress in double porous media with two immiscible fluids. Geophysical Research Letters 32, No. 15, doi:10.1029/2005GL023766 
10. Robinson RG, Tan TS, Dasari GR, Leung CF, Vijayakumar A. (2005) Experimental study of the behavior of a lumpy fill of soft clay. International Journal of Geomechanics ASCE; 5(2):125-137.

11. Karthikeyan M, Dasari GR, Tan TS. (2004) In situ characterization of a land reclaimed using big clay lumps. Canadian Geotechnical Journal; 41:242-256.

12. Hartlen J, Ingers C. (1981) Land reclamation using fine-grained dredged material. Proc. $10^{\text {th }}$ Int. Conf. on Soil Mech. and Found. Engrg., Stockholm; 145-148.

13. Manivannan R, Wong JC, Leung CF, Tan SA. (1998) Consolidation characteristics of lumpy fill, Proc. Centrifuge 98; 889-894.

14. Leung CF, Wong JC, Manivanann R, Tan SA. (2001) Experimental evaluation of consolidation behaviour of stiff clay lumps in reclamation fill. Geotechnical Testing Journal; 24(2):145-156.

15. Charles JA, Watts KS. (2001) Building on fill: geotechnical aspects. $2^{\text {nd }}$ edition; Construction Research Communications, London.

16. Charles JA. (2008) The engineering behaviour of fill materials: the use, misuse and disuse of case histories. Géotechnique 58(7):541-570.

17. Vaníček I, Vaníček M. (2008) Earth structures in transport, water and environmental engineering; Springer.

18. Herbstová V and Herle I. (2009) Structure transitions of clay fills in North-Western Bohemia. Engineering Geology 104:157-166.

19. Aifantis, E. C. (1977). Introducing a multi-porous medium. Dev. Mech. 8, 209-211.

20. Wilson, R.K. and Aifantis, E.C. (1982). On the theory of consolidation with double porosity. International Journal of Engineering Science 20(9):1009-1035. 
21. Khalili, N. and Valliapan, S. (1996). Unified theory of flow and deformation in double porous media. European Journal of Mechanics, A/Solids 15, No. 2, 321-336.

22. Yang, L.-A., Tan, T.-S., Tan, S.-A., Leung, C.-F. (2002). One-dimensional self-weight consolidation of a lumpy clay fill. Géotechnique 52, No. 10, 713-725.

23. Yang LA, Tan TS. (2009) One-dimensional consolidation of lumpy clay with non-linear properties. Géotechnique 55(3):227-235.

24. Doležalová, M. And Kořán, P. (2002). Micromechanical modelling of a dump material. The International Journal of Geomechanics 2, No. 1, 47-74.

25. Callari, C. And Federico, F. (2000). FEM validation of a double-porosity elastic model for consolidation of structurally complex clayey soils. International Journal for Numerical and Analytical Methods in Geomechanics 24, 367-402.

26. Koliji, A., Laloui, L. And Vulliet, L. (2009). Behaviour of unsaturated aggregated soil in oedometric conditions. Soils and Foundations 49, No. 3, 369-380.

27. Mašín D, Herbstová V, Boháč J. (2005) Properties of double porosity clayfills and suitable constitutive models. Proc. $16^{\text {th }}$ Int. Conf. ICSMGE, Osaka, Japan; 827-830.

28. Škopek J. (2001) Evaluation of fill compressibility by means of a trial embankment. Proc. of Int. Conf. Insitu Measurement of Soil Properties, Bali.

29. Škopek J, Boháč J. (2004) Site investigation by trial embankments. Proc. of ISC-2 on Geotechnical and Geophysical Site Characterization, Porto; 1571-1574.

30. Mašín D. (2007) A hypoplastic constitutive model for clays with meta-stable structure. Canadian Geotechnical Journal 44(3):363-375.

31. Lagioia, R. and Nova, R. (1995). An experimental and theoretical study of the behaviour of a calcarenite in triaxial compression. Géotechnique, 45(4): 633-648. 
32. Liu, M. D. and Carter, J. P. (2002). A structured Cam Clay model. Canadian Geotechnical Journal, 39: 1313-1332.

33. Baudet, B. A. and Stallebrass, S. E. (2004). A constitutive model for structured clays. Géotechnique, 54(4): 269-278.

34. Rouainia, M. and Muir Wood, D. (2000). A kinematic hardening constitutive model for natural clays with loss of structure. Géotechnique, 50(2): 153-164.

35. Kavvadas, M. and Amorosi, A. (2000). A constitutive models for structured soils. Géotechnique, 50(3): 263-273.

36. Burland, J. B. (1990). On the compressibility and shear strength of natural clays. Géotechnique, 40(3): 329-378.

37. Mašín D. (2005) A hypoplastic constitutive model for clays. International Journal for Numerical and Analytical Methods in Geomechanics 28(4):311-336.

38. Kolymbas, D. (1991). An outline of hypoplasticity. Archive of Applied Mechanics; 61:143151.

39. Tamagnini, C., Viggiani, G., and Chambon, R. (2000). A review of two different approaches to hypoplasticity. In D. Kolymbas (Ed.), Constitutive modelling of granular materials, pp. 107-144. Springer.

40. von Wolffesrdorff, P. A. (1996). A hypoplastic relation for granular materials with predefined limit state surface. Mechanics of Cohesive-Frictional Materials 1, 251-271.

41. Niemunis A. (1996). A visco-hypoplastic model for clay and its FE implementation. Resultats recents en mechanique des sols et des roches XI Colloque Franco-Polonais, Gdansk.

42. Huang W-X, Wu W, Sun D-A, Sloan S (2006) A simple hypoplastic model for normally 
compressed clay. Acta Geotechnica 1(1):15-27.

43. Niemunis, A., Grandas-Tavera, C. E. and Prada-Sarmiento, L. F. (2009). Anisotropic viscohypoplasticity. Acta Geotechnica 4(4): 293-314.

44. Roscoe KH, Burland JB (1968) On the generalised stress-strain behaviour of wet clay. In: Heyman J, Leckie FA (eds) Engineering plasticity. Cambridge University Press, Cambridge, pp 535-6.

45. Niemunis A, Herle I. (1997). Hypoplastic model for cohesionless soils with elastic strain range. Mechanics of Cohesive-Frictional Materials; 2:279-299.

46. Hájek V, Mašín D, Boháč J. (2009). Capability of constitutive models to simulate soils with different OCR using a single set of parameters. Computers and Geotechnics 36(4):655-664.

47. Herbstová V, Mašín D, Boháč J. (2005) Parameters for non-engineered colliery clayfills. Proc. Int. Conf. on Problematic Soils (GEOPROB), Famagusta, Cyprus; 335-342.

48. Najser J, Pooley E, Springman SM. (2009) Modelling of double porosity clays in a minicentrifuge. International Journal of Physical Modelling in Geotechnics 9(1):15-22.

49. Henriquez H. (2006 ) Sensitivity model for clayey spoil heaps - laboratory evaluation. MSc thesis, Univ Técnica de Lisboa - PřF UK Praha.

50. Springman SM, Laue J, Boyle R, White J, Zweidler A. (2001). The ETH Zurich Geotechnical Drum Centrifuge. International Journal of Physical Modelling in Geotechnics, 1(1), 59-70.

51. Schofield AN. (1980) Cambridge Geotechnical Centrifuge Operations. Géotechnique 30(2):227-268.

52. Najser J, Pooley E, Springman SM, Laue J, Boháč J. (2009) Mechanisms controlling the behaviour of double porosity clayfills - in situ and centrifuge study. Quarterly Journal of Engineering Geology and Hydrogeology; in print. 
53. Rodemann, D. (2008) Tochnog professional user's manual, http://www.feat.nl.

54. Gudehus, G., Amorosi, A., Gens, A., Herle, I., Kolymbas, D., Mašín, D., Muir Wood, D., Nova, R., Niemunis, A., Pastor, M., Tamagnini, C., Viggiani, G. (2008). The soilmodels.info project. International Journal for Numerical and Analytical Methods in Geomechanics 32, 1571-1572. 